\title{
A Review of Inorganic Scintillation Crystals for Extreme Environments
}

\author{
Chanho Kim ${ }^{1,2}{ }^{\mathbb{D}}$, Wonhi Lee ${ }^{2,3}{ }^{\mathbb{D}}$, Alima Melis ${ }^{4,5}$, Abdallah Elmughrabi ${ }^{3,6}$, Kisung Lee ${ }^{1,2,5}$, \\ Chansun Park $3,5,7, *$ D and Jung-Yeol Yeom $1,2,3,5, *$
}

1 Department of Bio-Convergence Engineering, Korea University, Seoul 02841, Korea; manngo@korea.ac.kr (C.K.); kisung@korea.ac.kr (K.L.)

2 Department of Bioengineering, Korea University, Seoul 02841, Korea; wheeliee@korea.ac.kr

3 Interdisciplinary Program in Precision Public Health, Korea University, Seoul 02841, Korea; iglobalthoughts@gmail.com

4 Department of Chemical \& Biological Engineering, Korea University, Seoul 02841, Korea; alima.melis@gmail.com

5 School of Biomedical Engineering, Korea University, Seoul 02841, Korea

6 Department of Bio-Microsystem Technology, Korea University, Seoul 02841, Korea

7 BK21 FOUR R\&E Center for Precision Public Health, Korea University, Seoul 02841, Korea

* Correspondence: parkcs@korea.ac.kr (C.P.); jungyeol@korea.ac.kr (J.-Y.Y.)

check for updates

Citation: Kim, C.; Lee, W.; Melis, A.; Elmughrabi, A.; Lee, K.; Park, C.; Yeom, J.-Y. A Review of Inorganic Scintillation Crystals for Extreme Environments. Crystals 2021, 11, 669. https://doi.org/10.3390/ cryst11060669

Academic Editor: Yuriy Zorenko

Received: 6 May 2021

Accepted: 8 June 2021

Published: 10 June 2021

Publisher's Note: MDPI stays neutral with regard to jurisdictional claims in published maps and institutional affiliations.

Copyright: (C) 2021 by the authors. Licensee MDPI, Basel, Switzerland. This article is an open access article distributed under the terms and conditions of the Creative Commons Attribution (CC BY) license (https:// creativecommons.org/licenses/by/ $4.0 /)$.

\begin{abstract}
In the past, the main research and use of scintillators in extreme environments were mainly limited to high energy physics and the well-logging industry, but their applications are now expanding to reactor monitoring systems, marine and space exploration, nuclear fusion, radiation therapy, etc. In this article, we review and summarize single-crystal inorganic scintillator candidates that can be applied to radiation detection in extreme environments. Crucial scintillation properties to consider for use in extreme environments are temperature dependence and radiation resistance, along with scintillators' susceptibility to moisture and mechanical shock. Therefore, we report on performance change, with a focus on radiation resistance and temperature dependence, and the availability of inorganic scintillator for extreme environments-high radiation, temperature, humidity and vibration-according to their applications. In addition, theoretical explanations for temperature dependence and radiation resistance are also provided.
\end{abstract}

Keywords: inorganic scintillation crystal; radiation detector; temperature dependence; radiation resistance

\section{Introduction}

Scintillators play a crucial role as radiation detection materials in various nuclear technologies and radiation applications, such as medical imaging, well logging, homeland security, marine and space exploration, and high energy physics (HEP). They indirectly detect radiation and are usually coupled with a photo-sensor. In a scintillator, the energy deposited by incoming radiation is converted into light photons, which are detected by a photo-sensor and converted into an electrical signal. Generally, scintillators can be classified into organic and inorganic, and the scintillator type used in a radiation detector is determined by the type of radiation particle to be measured as well as the purpose of radiation detection.

Organic scintillators, such as Stilbene and liquid scintillators, have an excellent pulse shape discrimination ability to distinguish between gamma rays and neutrons or alpha particles. Thus, they are mainly used to detect neutrons or accelerated charged particles, such as protons and alpha particles [1,2]. However, owing to the low density and detection efficiency (stopping power) of organic scintillators, inorganic ones are preferred when measuring X-rays or gamma rays. In terms of temperature, the melting points of inorganic scintillators are typically higher than those of organic scintillators, and most inorganic 
scintillators are grown in high-temperature furnaces. Because of their higher melting points, inorganic scintillators are more resistant to high temperatures than are organic scintillators [3].

Inorganic scintillators are primarily ionic solids and composed of high-density crystals. They can be classified into two categories (single-crystals and polycrystalline ceramics), with the former typically exhibiting better optical properties at the expense of fabrication costs $[4,5]$. Polycrystalline ceramics' relatively poorer optical properties (transparency) often limit their applications to lower energy radiation detection where smaller-sized scintillators can be used.

Single-crystal inorganic scintillators are preferred in fields requiring radiation detection under extreme conditions (high radiation, temperature, humidity, vibrations, etc.), such as well logging, HEP, nuclear reactor monitoring, and space exploration. In these applications, large-sized scintillators are often used to detect and measure high-energy radiation under harsh conditions.

In the well logging industry, the growing demand for fossil fuels worldwide has led to deeper drilling to search for new fuel sources, and the increasing depth of wells creates more challenging downhole environments. In addition, future HEP experiment environments are expected to be harsher in terms of radiation exposure. In this respect, development of new scintillators that can withstand higher temperatures and research on existing scintillators for use in extreme environments (high radiation, vibration conditions, humidity, etc.) are ongoing.

Therefore, we review and summarize single-crystal inorganic scintillator candidates, which can be used in several applications requiring radiation detection in extreme environments. Focus is placed on factors that directly affect scintillation properties (i.e., temperature dependence and radiation resistance) and physical properties such as susceptibility to mechanical shock (vibration) and hygroscopicity are also considered depending on application fields.

The temperature dependence of a scintillator is typically assessed by evaluating changes in the light yield of the scintillator with varying temperatures. Other general properties of the scintillator, including decay time and energy resolution, are also often considered. Similarly, the radiation resistance of a scintillator is assessed by the change in light yield or optical transmittance of the scintillator with respect to radiation dose. Therefore, radiation dose rate dependence of various scintillator candidates and radiation damage recovery via thermal annealing are also reviewed in this study. In addition, in applications where the detectors are exposed to high humidity, such as in a nuclear power plant (NPP) in the event of a severe accident, or high vibrations (such as well logging and space exploration), the hygroscopicity and mechanical susceptibility of the crystal (and subsequent components such as photosensor) should be considered.

The abovementioned characteristics are reviewed according to their application fields, such as well-logging, HEP, and reactor monitoring systems. In this article, in addition to performance changes and availability of scintillators for extreme environments (high radiation and temperature), we provide theoretical explanations for the temperature dependence and radiation resistance of scintillators.

\section{Theoretical Background}

\subsection{Temperature Dependence of Inorganic Scintillator}

Generally, the light yield of a scintillator gradually decreases (or increases for a short range for some scintillators) with increasing temperature, and above a certain temperature, it decreases abruptly [6], attributable to the luminescent thermal quenching phenomenon observed at the luminescent center as temperature increases. The main cause for a scintillator's thermal quenching is nonradiative transition via electron-phonon coupling, thermal ionization, and thermal quenching due to interionic processes [7].

Nonradiative transitions are reactions where excited electrons created by the impinging radiation return to the ground state through vibrational relaxation in the form of heat 
or vibration, rather than through a scintillation process as shown in Figure 1a. Such a phenomenon can be explained through the quantum mechanical single-configurationalcoordinate (SCC) model [8-10]. As shown in Figure 1b, nonradiative transitions occur when sufficient heat energy (delta E) related to vibrational excitation is supplied. In the SCC model, such reactions occur at the point where the energy is supplied to the electrons in the $5 \mathrm{~d}$ band and these electrons are excited to the cross point of the $5 \mathrm{~d}$ and $4 \mathrm{f}$ energy curves, and the electrons move down to the ground state afterward. Therefore, unlike radiative transitions, nonradiative transitions are Arrhenius-dependent reactions, and, as depicted in the following equation, the nonradiative transition rate $\left(R_{n r}\right)$ increases with temperature $[6,8]$.

$$
R_{n r}=A_{n r} \times e^{-(\Delta E / k T)},
$$

where $A_{n r}$ represents the event rate of nonradiative transitions; $k$ and $T$ represent the Boltzmann constant and temperature, respectively; $\Delta E$ is the energy required for the excited electrons to reach the cross point of the $5 \mathrm{~d}$ and $4 \mathrm{f}$ potential energy curves.

(a)

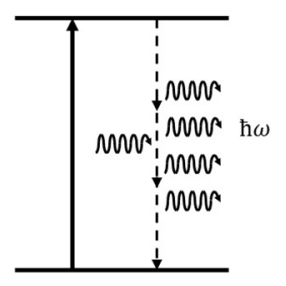

(b)

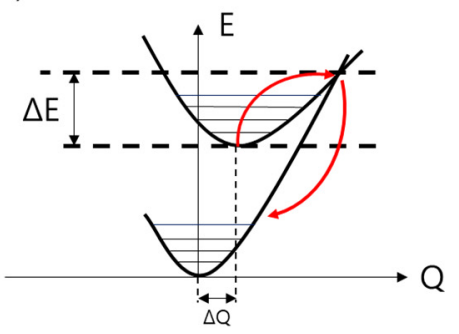

(c)

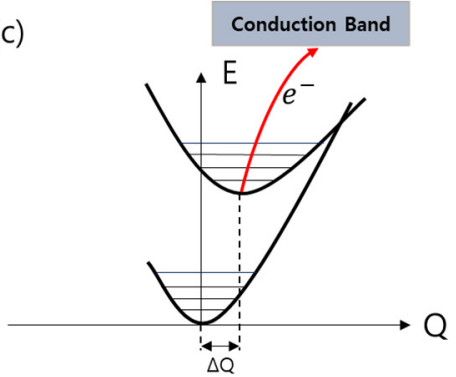

Figure 1. Thermal quenching mechanisms in inorganic scintillators: (a) multiphonon relaxation and single configurational coordinate diagram illustrating (b) nonradiative transition and (c) thermal ionization process. Reproduced with permission of Ref. [11].

Thermal ionization, a major factor influencing thermal quenching, is the process of electron transition from the excited states to the conduction band of the host material, not to the ground states (Figure 1c). In addition, excited electrons are captured by traps (such as substitutional impurities, atoms, vacancies, and antisite defects in the host material) via de-excitation processes [12,13]. The probability of these trapped electrons being thermally released and excited back to the conduction band is low. Rather, the trapped electrons' energy is mostly released in the form of low-energy photons, such as infrared rays, or undergoes nonradiative vibration relaxation and eventually reduces the luminescence of scintillators. The rate of thermal ionization depends on the Arrhenius equation and increases with temperature [7].

$$
R_{i}=A_{i} \times e^{-\left(\Delta E_{i} / k T\right)},
$$

where $A i$ is the rate coefficient [14], and $\Delta E i$ is the required energy for the excited electrons to reach the conduction band. Therefore, $\Delta E i$ relates to the energy level of the conduction band, and a smaller $\Delta E i$ causes stronger thermal ionization quenching. Similar to the nonradiative transition rate, the thermal ionization rate also increases as temperature increases as indicated by the Arrhenius equation. However, the rate of nonradiative transition is affected by the $\Delta E$ (the energy required for the excited electrons to reach the cross point of the $5 \mathrm{~d}$ and $4 \mathrm{f}$ potential energy curves.). On the other hand, the thermal ionization rate is mainly affected by the energy gap between $5 \mathrm{~d}$ and the conduction band. The energy levels of the conduction and valence bands vary with the compositions of the host material (Figure 2). According to a study that investigated the binding energies in lanthanide and garnet host band states [15] by controlling the constituent proportions of $\mathrm{Al}$ and $\mathrm{Ga}$ in $\mathrm{RE}_{3}\left(\mathrm{Al}_{1-\mathrm{x}} \mathrm{Ga}_{\mathrm{x}}\right)_{5} \mathrm{O}_{12}$ garnet compounds (hence adjusting the energy levels 
of the conduction and valence bands), an increase in thermal ionization rate along with a decrease in conduction band level was confirmed.

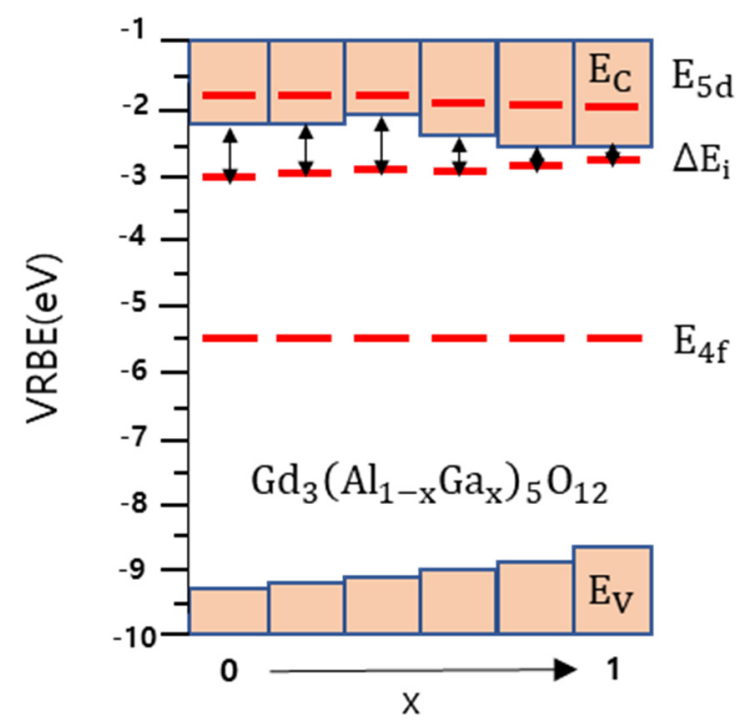

Figure 2. Vacuum referred binding energy (VRBE) for electrons in the $4 \mathrm{f}$ ground state and first two $5 \mathrm{~d}$ excited states of $\mathrm{Ce}^{3+}$ in $\mathrm{RE}_{3}\left(\mathrm{Al}_{1-\mathrm{x}} \mathrm{Ga}_{\mathrm{x}}\right)_{5} \mathrm{O}_{12}$ garnet compounds. Reproduced with permission of Ref. [15].

Apart from intraionic transitions, nearby optical centers are influenced by thermal energy, reducing the emission yield. A luminescent center ion can lose its excitation energy to the neighboring optical center through energy transfer. As the charge transfer state is created between ground and excited states, it acts as a bridge to create the cross point where emission quenching starts. The probability of energy transfer has been reported to depend on the spectral overlap of the spectra of donor emission and acceptor absorption. The degree of spectral overlaps tends to increase with temperature as vibronic coupling causes the thermal broadening of the spectrum, which increases energy transfer. Lanthanide dopant ions tend to involve multiple energy transfer steps, inducing energy hopping to reach a quenching center far apart. Because the energy transfer mechanism is extensive, temperature dependency on the thermal quenching process is rather complex [11].

In summary, thermal quenching (such as nonradiative transition or thermal ionization) occurs as temperature increases, decreasing scintillators' light yields. Therefore, applications requiring exposure to high temperatures require careful selection of scintillators, considering their temperature-dependent properties.

\subsection{Radiation Damage Mechanism}

All scintillators are susceptible to damage by radiation. Possible effects of scintillator damage are (1) radiation-induced absorption (the formation of color centers), (2) radiation-induced phosphorescence (afterglow), and (3) damage to the scintillation mechanism [16]. Damage to the scintillation mechanism may degrade the intrinsic light yield of a scintillator and change the emission and absorption spectra. However, in studies of gamma ray-induced radiation damage effects on various scintillators, there were no experimental data supporting radiation-damaging scintillation mechanisms [17]. Most studies on radiation damage to scintillators reported the former two effects (radiation-induced phosphorescence (afterglow) and radiation-induced absorption) as the main reasons for performance degradation. Readout noise may increase due to radiation-induced phosphorescence. However, the most crucial factor affecting scintillation properties upon radiation exposure is radiation-induced absorption. Radiation-induced absorption refers to radiation damage in which color centers are created by impinging radiation that trap light photons and consequently reduce the light output from the scintillator. 
The light output degradation of a radiation-damaged scintillator can reduce the stability and reliability of radiation measurements but can be compensated for via calibration through light monitoring $[18,19]$. Moreover, the concentration of color centers may decrease spontaneously and recover at room temperature (RT) or higher, depending on the scintillator. Since radiation detectors used in high radiation environments are often calibrated using a light monitoring system, color-center annihilation at RT is an essential property of a radiation-resistant scintillator. Thus, radiation damage to a scintillator depends on the radiation dose rate and decrease (recovery) rate of color centers. If the concentration of color centers in a radiation-damaged scintillator decreases at RT, the scintillator's degree of damage will show dependence on the dose rate. However, if the color centers do not diminish at RT, the amount of radiation damage to the scintillator will relate to the total radiation dose regardless of the dose rate. Generally, scintillators that recover slowly at RT are more suitable for use in high-radiation environments because they are easier to calibrate [16]. Because color centers at high temperatures (usually above $300{ }^{\circ} \mathrm{C}$ ) may be eliminated at rapidly, thermal annealing can restore radiation damage suffered by scintillators $[20,21]$. Figure 3 shows the color change of scintillators before and after gamma-ray irradiation, as well as after thermal annealing.

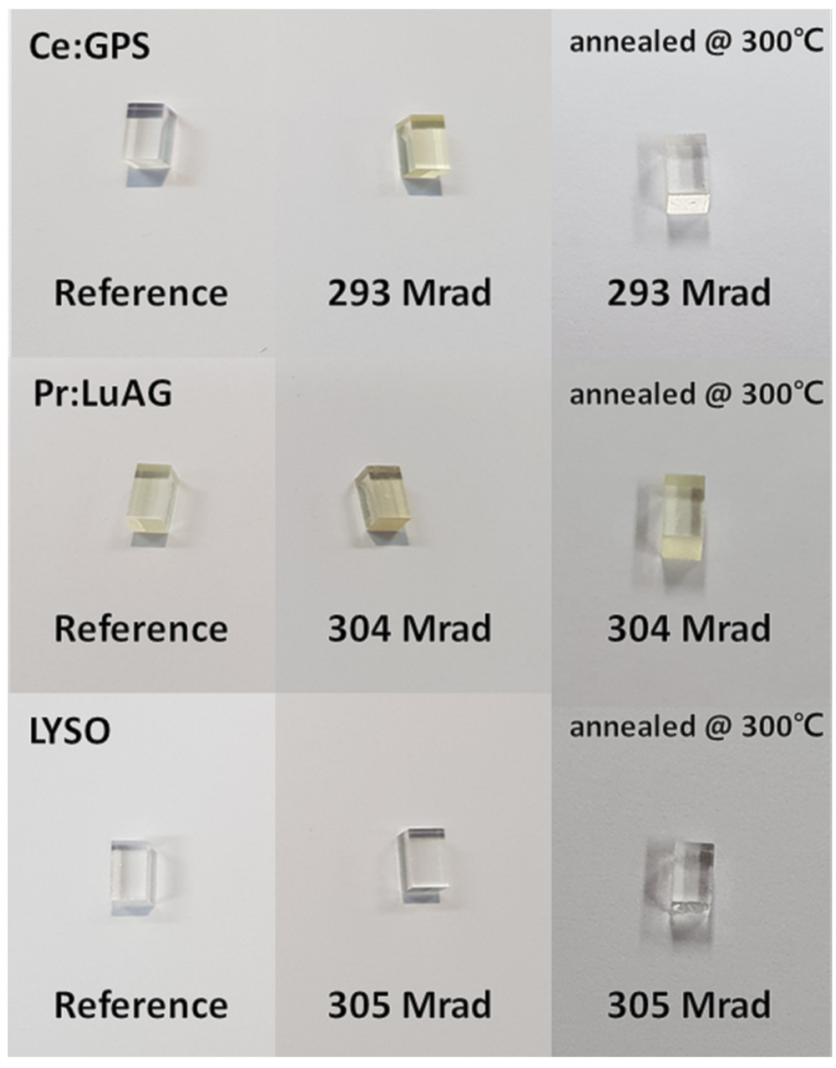

Figure 3. Changes in the colors of Ce:GPS, Pr:LuAG, and LYSO scintillators before and after gammaray irradiation and thermal annealing at different radiation doses. Reproduced with permission of Ref. [22].

Therefore, in fields where scintillators are exposed to large amounts of radiation, in addition to considering the reduction in light output of scintillators due to radiationinduced absorption, the dose rate dependence and radiation damage recovery of the scintillator should be considered. 


\section{Scintillation Crystal Applications in Extreme Environments \\ 3.1. Well-Logging Industry}

For decades, there has been a steady demand for high-temperature radiation detectors to be used in the well-logging industry, and oil wells need to be drilled deeper to access new fuel sources. The deeper the well, the harsher the downhole environment (temperature) in which nuclear measurements need to be made. Furthermore, in the case of logging while drilling implementations, the radiation detector may experience high levels of vibration and shock. In general, the downhole environment is known to be at a temperature of about $175^{\circ} \mathrm{C}$ and a pressure of 20,000 psi, and the vibration level and shock level caused by drilling are $\sim 30 \mathrm{~g}$ RMS and $\sim 700 \mathrm{~g}$, respectively [23]. Therefore, radiation detectors used in the well-logging industry must maintain their performance in terms of scintillation properties (such as emission spectrum, decay time, and light output) at high temperatures. In addition, radiation detectors have to operate at high levels of vibration and shock, so the brittleness of the scintillator should also be considered.

There have been numerous studies on the temperature dependence of single-crystal scintillators for the well-logging industry. NaI:Tl-a traditional halide scintillator-is a commonly used scintillator in nuclear well-logging tools due to its high light output and good temperature dependence [24]. The temperature dependence of NaI:Tl was evaluated up to $300{ }^{\circ} \mathrm{C}$ [25]; NaI:Tl showed acceptable temperature dependence at temperatures between $175^{\circ} \mathrm{C}$ and $200^{\circ} \mathrm{C}$. Although $\mathrm{NaI}(\mathrm{Tl})$ has been used in the well-logging industry for more than $60 \mathrm{yr}$ because of its performance at high temperatures, high light yield, and low cost, it has a few critical drawbacks, such as low detection efficiency. Moreover, it requires thorough packaging due to its hygroscopicity and fragility [26].

The increasing desire for more efficient high-temperature-resistant scintillators has led to the discovery of new halide scintillators, such as $\mathrm{LaBr}_{3}: \mathrm{Ce}$ and $\mathrm{LaCl}_{3}: \mathrm{Ce}$, which were first introduced in the early $2000 \mathrm{~s}$. These halide scintillators have received huge attention due to their excellent properties such as excellent light yield, good energy resolution, and high density. Regarding temperature resistance, $\mathrm{LaBr}_{3}: \mathrm{Ce}$ was reported to show $8 \%$ energy resolution at $175{ }^{\circ} \mathrm{C}$, superior to the $9.9 \%$ energy resolution of NaI:Tl at RT. Along with $\mathrm{LaBr}_{3}: \mathrm{Ce}, 10 \%$ doped $\mathrm{LaCl}_{3}$ showed even more impressive scintillation characteristics over a wide range of temperatures. For example, $\mathrm{LaCl}_{3}: \mathrm{Ce}$ maintains an almost constant light yield from 100 to $600 \mathrm{~K}$, reaching its maximum at $500 \mathrm{~K}$ [27]. Thus, these two scintillators can replace NaI:Tl scintillator in well-logging, considering that they both have a similar drawback as NaI:Tl of being extremely sensitive to humidity [28] and being very brittle [29].

Recently, the $\mathrm{Cs}_{2} \mathrm{LiYCl}_{6}$ :Ce (CLYC) scintillator has drawn attention as a promising scintillator for well-logging because of its ability to detect both gamma rays and neutrons. At $120^{\circ} \mathrm{C}, \mathrm{CLYC}$ 's light yield retention, relative to that at RT, is significantly better than that of NaI:Tl. At $175^{\circ} \mathrm{C}, \mathrm{CLYC}$ maintained a value of $78 \%$ of that at RT, whereas NaI:Tl was only 55\% [30]. Moreover, CLYC's neutron detection capability maintains its decay time and light yield for neutron particles at temperatures up to $150{ }^{\circ} \mathrm{C}$ and only showed slight degradation at higher temperatures, making it a suitable scintillator for well-logging using neutron radiation [31].

Another major scintillator group that can be used in well-logging is oxide scintillators. Among oxide scintillators, the temperature dependence of the Ce:GSO scintillator was studied in 1991, and it demonstrated a high light output even at $175^{\circ} \mathrm{C}$ [32]. In addition, Ce:YAP scintillator discovered in the 1980s [33] has many attractive properties, such as reasonably high density, fast decay, negligible afterglow, high light yield, and an excellent energy resolution of $4.4 \%$ for $662 \mathrm{keV}$ gamma radiation. At $150{ }^{\circ} \mathrm{C}$, the light output of Ce:YAP scintillator is half of that at RT. Generally, this scintillator shows a constant scintillation response with temperature change [34].

Some of the newly developed oxide scintillators have demonstrated potentials to be used in the well-logging industry. The Ce:GPS scintillator was first introduced in 2007 [35] and is known to have excellent energy resolution, light yield, and temperature dependence. The light yield of Ce:GPS was almost consistent from RT up to approximately 
$250{ }^{\circ} \mathrm{C}$ [22]. The light yield of Pr:LuAG, another scintillator known to have excellent temperature resistance, shows only slightly lower light output at $225{ }^{\circ} \mathrm{C}$ than at $50{ }^{\circ} \mathrm{C}$. However, compared with Ce:GPS, the Pr:LuAG scintillator has a relatively low light yield and possesses intrinsic radioactivity and short peak emission wavelength (306 nm). Therefore, the Ce:GPS scintillator is expected to show more excellent performance than the Pr:LuAG scintillator in high-temperature environments, including well-logging. Another scintillator-Ce:LuAP — had an observable photopeak at a temperature of $395^{\circ} \mathrm{C}$, and the performance at elevated temperatures indicated Ce:LuAP has potential in well-logging applications [36].

Vibration often accompanies well-logging, and vibration effects can be mitigated by selecting a robust scintillator or through better packaging of the radiation detector as a whole. Oxide based scintillators (such as Ce:YAP, YAG, etc.) are relatively less brittle than halide scintillators [37], but most halide scintillators, including lanthanum halide and elpasolite, are extremely brittle $[29,38]$. For example, $\mathrm{NaI}$ rates 2 on the Moh hardness scale, but LuAG(8.5), YAG (8.5), and YAP(8.6) are high on the Moh hardness scale [39]. Therefore, radiation detectors have to be properly packaged to withstand the vibration and the shock during geophysical oil logging operations. In particular, when using a halide based scintillator, it is necessary to improve the packaging by employing an internal shock resistant buffer. A list of suitable scintillators for the well-logging industry, along with their main characteristics, is presented in Table 1.

Table 1. Scintillator list and critical parameters for radiation detector used in the welllogging industry.

\begin{tabular}{|c|c|c|c|c|c|}
\hline Crystal & $\begin{array}{l}\text { Light Yield } \\
\text { (Photons/MeV) }\end{array}$ & $\begin{array}{l}\text { Density } \\
\left(\mathrm{g} / \mathrm{cm}^{3}\right)\end{array}$ & $\begin{array}{l}\text { Relative Light } \\
\text { Output }{ }^{1}\end{array}$ & Hygroscopicity & Ref \\
\hline NaI:Tl & 38,000 & 3.67 & $55 \%$ at $175^{\circ} \mathrm{C}$ & Hygroscopic & [25] \\
\hline $\mathrm{LaBr}_{3}: \mathrm{Ce}$ & 65,000 & 5 & $90 \%$ at $175^{\circ} \mathrm{C}$ & Hygroscopic & [28] \\
\hline $\mathrm{LaCl}_{3}: \mathrm{Ce}$ & 49,000 & 3.86 & $100 \%$ at $225^{\circ} \mathrm{C}$ & Hygroscopic & [27] \\
\hline CLYC & $\sim 20,000$ & 3.31 & $78 \%$ at $175^{\circ} \mathrm{C}$ & Hygroscopic & [25] \\
\hline GSO:Ce & 13,000 & 6.71 & $60 \%$ at $150{ }^{\circ} \mathrm{C}$ & Non-hygroscopic & [32] \\
\hline Ce:YAP & $\sim 24,000$ & 5.5 & $50 \%$ at $150{ }^{\circ} \mathrm{C}$ & Non-hygroscopic & {$[34,40]$} \\
\hline Ce:GPS & 30,000 & 5.5 & $100 \%$ at $250^{\circ} \mathrm{C}$ & Non-hygroscopic & {$[22,35]$} \\
\hline Pr:LuAG & $\sim 20,000$ & 6.7 & $70 \%$ at $225^{\circ} \mathrm{C}$ & Non-hygroscopic & {$[22,36]$} \\
\hline Ce:LuAP & $\sim 4300$ & 8.34 & $200 \%$ at $200^{\circ} \mathrm{C}$ & Non-hygroscopic & [41] \\
\hline
\end{tabular}

${ }^{1}$ Relative light output compared with that at RT.

\subsection{HEP}

In HEP, inorganic scintillators are essential for most radiation detectors in calorimeters, both existing and under development. The radiation involved in HEP is typically highenergy photons and particles in large numbers (high fluence rate). Therefore, characteristics required of detectors in calorimeters include high detection efficiency (density), fast decay time, good energy resolution, and radiation resistance for precise measurements of large numbers of high-energy radiation [42]. In HEP, scintillator light yield is secondary, as the energies involved are high, leading to a sufficiently large number of light photon emission during detection. Common inorganic scintillators that compose calorimeters used in HEP experiments include $\mathrm{CsI}$ (undoped), $\mathrm{BGO}$, and $\mathrm{PbWO}_{4}$ (PWO). Of these, the Compact Muon Solenoid (CMS) particle detector (composed of 75,848 PWO scintillators) has a total size of $11 \mathrm{~m}^{3}$, and is the largest among the used calorimeters. With its excellent energy resolution (for the target high energy radiations) and detection efficiency (high density), the CMS PWO calorimeter played an essential role in discovering the Higgs boson via CMS experiments [43]. Future HEP experiment environments will be even higher radiation environment; thus, bright, dense, and fast scintillator detectors with excellent radiation hardness are required. As mentioned in Section 2.2, the light output of scintillators can decrease under high radiation conditions. As expected, a significant loss of light output from the PWO scintillator was observed in the CMS PWO calorimeter [44]. To operate 
in the High-Luminosity Large Hadron Collider (HL-LHC), a scintillator must survive an absorbed dose of $100 \mathrm{Mrad}(100 \mathrm{Mrad})$, a hadron fluence of $6 \times 10^{14} \mathrm{~cm}^{-2}$, and a fast neutron fluence of $3 \times 10^{15} \mathrm{~cm}^{-2}$ [45]. Numerous studies have investigated the degree of radiation damage on various inorganic scintillators between radiation doses ranging between 0 and 340 Mrad to find a scintillator that can survive at this level.

The light output of an undoped CsI decreased to $30 \%$ of its original value (decrease of $70 \%$ ) after a gamma-ray irradiation dose of 1 Mrad but showed only an approximately $20 \%$ light output drop after a dose of $100 \mathrm{krad}$, indicating that the undoped CsI had radiation hardness against gamma-ray irradiation up to a $100 \mathrm{krad}$ dose [46,47]. Since the radiation damage of the undoped CsI was not recovered at RT, it was dose-rate independent. Therefore, it is possible to calibrate an undoped CsI calorimeter using light monitoring. In addition, undoped CsI has a fast decay time of approximately $30 \mathrm{~ns}$ and is suitable for mass production because of its low manufacturing cost. These advantages made undoped CsI to be selected as the scintillator in the calorimeter of Fermilab's KTeV experiment [48].

Moreover, the radiation damage of BGO [49] and PWO [50] recovers at RT after several hours or weeks, so they are dose-rate dependent. The light output of BGO and PWO scintillators, respectively, decreased to $45 \%$ and $30 \%$ of their original values at a 120-Mrad dose.

Studies regarding proton and neutron irradiation on PWO scintillators have also been conducted [51]. In this study, the PWO scintillator had an induced absorption length of $\sim 15 \mathrm{~m}^{-1}$ after proton irradiation with a fluence of $5 \times 10^{13} \mathrm{~cm}^{-2}$, whereas the induced absorption length of PWO was $0.3 \mathrm{~m}^{-1}$ at a gamma-ray dose of $5 \mathrm{Mrad}$, which showed that PWO exhibited less radiation hardness for protons compared with gamma rays. In recent neutron irradiation experiment of $\mathrm{PWO}$, approximately $86 \%$ of the light output loss was observed in PWO after $1.6 \times 10^{15}$ fast neutrons $/ \mathrm{cm}^{-2}$ irradiation [52]. In the same study, the LYSO scintillator showed significantly higher radiation hardness for neutrons compared with the PWO scintillator, with less than $25 \%$ light loss observed even after irradiation of up to $9 \times 10^{15}$ fast neutrons $/ \mathrm{cm}^{-2}$. LYSO maintained $75 \%$ light output even after 120 Mrad of gamma-ray irradiation, and the radiation damage of LYSO was dose-rate independent [47]. Following these results, LYSO crystals were proposed as the scintillation materials for an LYSO/W Shashlik sampling calorimeter in the CMS upgrade for the HL-LHC [53], and total-absorption LYSO crystal calorimeters were proposed for the SuperB experiment in Europe [54] and Mu2e experiment at Fermilab [55].

The radiation resistance of other oxide inorganic scintillators, such as Ce:GPS, GSO, and Pr:LuAG, has also been investigated. Ce:GSO scintillators have excellent radiation resistance and fast decay time. It was reported that Ce:GSO did not show a noticeable decrease in light yield up to 100 Mrad [56], but another study reported an increase in the light output of Ce:GSO after gamma-ray irradiation [57]. The Ce:GPS scintillator was reported to show $57 \%$ and $15 \%$ light output of their original values after gammaray irradiation of approximately 68 and 369 Mrad, respectively; in addition, Pr:LuAG scintillator showed $46 \%$ and $36 \%$ light output at gamma-ray irradiation of approximately 70 and 382 Mrad, respectively [22]. According to [1], in the order of increasing radiation resistance, are thallium-activated alkali halides, $\mathrm{CsF}, \mathrm{BGO}, \mathrm{YAO}, \mathrm{CeF}_{3}, \mathrm{BaF}_{2}$, and GSO. Table 2 summarizes the essential properties of selected scintillators and their radiation hardness regarding HEP experiments. 
Table 2. Performances of selected scintillators and critical parameters for HEP experiments.

\begin{tabular}{|c|c|c|c|c|c|}
\hline Crystal & $\begin{array}{c}\text { Decay } \\
\text { Time (ns) }\end{array}$ & $\begin{array}{l}\text { Density } \\
\left(\mathrm{g} / \mathrm{cm}^{3}\right)\end{array}$ & $\begin{array}{c}\text { Relative Light Output } 1 \\
\text { at Radiation Dose (\%) }\end{array}$ & $\begin{array}{c}\text { Dose-Rate } \\
\text { Dependence }\end{array}$ & Ref \\
\hline LYSO & 40 & 7.4 & $\begin{array}{c}89 \% \text { at } 1 \mathrm{Mrad} \\
75 \% \text { at } 120 \mathrm{Mrad}\end{array}$ & $x$ & {$[47,58]$} \\
\hline Pr:LuAG & 20 & 6.7 & $46 \%$ at $70 \mathrm{Mrad}$ & $\mathrm{O}$ & {$[22,59]$} \\
\hline Ce:GPS & 46 & 5.5 & $57 \%$ at $68 \mathrm{Mrad}$ & $x$ & [22] \\
\hline GSO & 30 & 6.7 & $\begin{array}{c}100 \% \text { at } 100 \text { Mrad (No } \\
\text { degradation) }\end{array}$ & $\mathrm{O}$ & {$[56,57]$} \\
\hline PWO & $\begin{array}{c}30 \\
6\end{array}$ & 8.3 & $30 \%$ at $120 \mathrm{Mrad}$ & $\mathrm{O}$ & [50] \\
\hline Undoped-CsI & 30 & 4.5 & $\begin{array}{c}80 \% \text { at } 100 \mathrm{krad} \\
30 \% \text { at } 1 \mathrm{Mrad}\end{array}$ & $x$ & [46] \\
\hline BGO & 300 & 7.1 & $45 \%$ at $120 \mathrm{Mrad}$ & $\mathrm{O}$ & [49] \\
\hline $\mathrm{BaF}_{2}$ & 650 & 4.9 & $40 \%$ at $120 \mathrm{Mrad}$ & $X$ & [60] \\
\hline
\end{tabular}

${ }^{1}$ Compared with the radiation undamaged scintillator.

As future HEP experiment environments will be harsher in terms of radiation exposure, it is expected that fast, dense, bright, and radiation-resistant scintillators will continue to play a crucial role in HEP experiments. Therefore, related R\&D of radiation-resistant scintillators is expected to continue.

\subsection{Nuclear Reactor Monitoring System in Nuclear Power Plant}

Nuclear power plants (NPPs) have been constructed globally to meet the ever-increasing demand for energy. As of 2020, 442 NPPs were operating in 30 countries, and the commissioning of 52 new NPPs in 15 countries is underway [61]. As the number of NPPs in operation and under construction increases, there is an increasing interest in the safety of these plants. In particular, after the Three Mile Island accidents in 1979 and the Chernobyl disaster in 1986, accident management has been crucial for NPPs. After these accidents, an NPP accident monitoring system had been designed and installed using guidelines that included the impact of lessons learned from the accidents. Despite this, another severe accident at the Fukushima Daiichi NPP in March 2011 resulted in many severe failures, such as power outages in several monitoring devices, reactor core damage, and hydrogen explosions. Therefore, it was necessary to review the standards of equipment used for NPP accident monitoring. Accordingly, IAEA established an action plan for nuclear safety in response to the Fukushima Daiichi accident and provided instructions for severe accident monitoring systems in NPPs [62].

These guidelines focused on maintaining the integrity of the reactor core, reactor pressure vessel (RPV), and reactor containment vessel (CV) conditions due to the experience acquired from the damaged Fukushima Daiichi reactor CV. In this guideline, the severe accident plant state for boiling water reactor (BWR) and pressurized water reactor (PWR) plants were classified into four severe accident states (SAs). The definitions and environmental conditions of each state suggested in the guideline are shown in Table 3 [63].

SA3 (RPV injury) was divided into two states. One is SA3a, which included the type of accident that occurred at the Fukushima Daiichi NPP, and the other is SA3b, which was considered beyond SA3a. SA3a and SA3b were differentiated based on the success of the accident management strategy (early water injection within $24 \mathrm{hr}$ after core damage). These severe state stages were intended to identify the criteria for designing accident monitoring devices necessary to facilitate the mitigation of accident progression. Therefore, equipment capable of monitoring the reactor must operate under high temperature and radiation conditions specified in Table 3. 
Table 3. Severe accident states-SA1 to SA3b-for NPP reactors.

\begin{tabular}{|c|c|c|c|c|c|}
\hline \multicolumn{2}{|c|}{ Reactor Type and Location } & \multirow[t]{2}{*}{ SA1 $^{1}$} & SA2 & \multicolumn{2}{|c|}{ SA3 } \\
\hline \multirow{3}{*}{ BWRs } & Plant condition & & $\begin{array}{l}\text { Core damage } \\
\text { RPV damage }\end{array}$ & $\begin{array}{l}\text { Core damage } \\
\text { RPV damage } \\
\text { PCV damage }\end{array}$ & $\begin{array}{l}\text { Core damage } \\
\text { RPV damage } \\
\text { PCV damage }\end{array}$ \\
\hline & Condition $^{2}$ in $\mathrm{PCV}^{3}$ & $\begin{array}{c}171^{\circ} \mathrm{C} \\
500 \text { Mrad } / 6 \text { month } \\
\text { Steam }\end{array}$ & $\begin{array}{c}300^{\circ} \mathrm{C} \\
500 \text { Mrad } / 6 \text { month } \\
\text { Steam }\end{array}$ & $\begin{array}{c}700^{\circ} \mathrm{C} \\
500 \text { Mrad } / 6 \text { month } \\
\text { Steam }\end{array}$ & $\begin{array}{c}1000^{\circ} \mathrm{C} \\
500 \mathrm{Mrad} / 6 \text { month } \\
\text { Steam }\end{array}$ \\
\hline & Condition outside PCV & $\begin{array}{c}66^{\circ} \mathrm{C} \\
30 \text { Mrad } / 6 \text { month } \\
100 \%\end{array}$ & $\begin{array}{c}66^{\circ} \mathrm{C} \\
30 \mathrm{Mrad} / 6 \text { month } \\
\text { Steam }\end{array}$ & $\begin{array}{c}100{ }^{\circ} \mathrm{C} \\
200 \text { Mrad } / 6 \text { month } \\
\text { Steam }\end{array}$ & $\begin{array}{c}100{ }^{\circ} \mathrm{C} \\
200 \mathrm{Mrad} / 6 \text { month } \\
\text { Steam }\end{array}$ \\
\hline \multirow{3}{*}{ PWRs } & Plant condition & $\begin{array}{c}\text { Core damage } \\
\text { (Meltdown) }\end{array}$ & $\begin{array}{l}\text { Core damage } \\
\text { RV damage }\end{array}$ & $\begin{array}{l}\text { Core damage } \\
\text { RV damage } \\
\text { CV damage }\end{array}$ & $\begin{array}{l}\text { Core damage } \\
\text { RV damage } \\
\text { CV damage }\end{array}$ \\
\hline & Condition in $\mathrm{CV}^{4}$ & $\begin{array}{c}190^{\circ} \mathrm{C} \\
- \\
100 \%\end{array}$ & $\begin{array}{c}200{ }^{\circ} \mathrm{C} \\
200 \mathrm{Mrad} / \mathrm{yr} \\
100 \%\end{array}$ & $\begin{array}{c}200{ }^{\circ} \mathrm{C} \\
200 \mathrm{Mrad} / \mathrm{yr} \\
100 \%\end{array}$ & $\begin{array}{c}300{ }^{\circ} \mathrm{C} \\
200 \mathrm{Mrad} / \mathrm{yr} \\
100 \%\end{array}$ \\
\hline & Condition outside CV & $\begin{array}{c}\text { Atmospheric } \\
\text { condition }\end{array}$ & - & - & - \\
\hline
\end{tabular}

${ }^{1} \mathrm{SA}$ — severe accident. ${ }^{2}$ Environmental condition-Maximum temperature, radiation dose, and humidity, respectively. ${ }^{3}$ PCV-primary containment vessel. ${ }^{4} \mathrm{CV}-$ containment vessel.

Because of the extreme environment around reactors, the radiation monitoring system of NPPs usually monitors the radiation level in specific areas (area radiation monitoring system) or radioactive fluid and effluent in the plant (process radiation monitoring system) outside the containment rather than monitoring the reactor within the containment. In this section, we present potential scintillators that could be used as radiation detection materials for nuclear reactor monitoring within the containment of PWR.

As described above, unlike in fields such as HEP and well-logging, scintillators used in reactor monitoring systems must be resistant to both high temperature and radiation. In addition, since radiation damage of a scintillator can be recovered at high temperatures, one should also consider scintillator radiation damage recovery via thermal annealing. On the other hand, during a nuclear accident severe accident, the humidity in the NPP containment building is expected to be very high $(100 \%$ or steam) and the hygroscopicity of scintillator should also be considered (Tables 3 and 4). Furthermore, according to the guideline by IAEA [64], radiation detectors for use during a several accident are expected to be grouped in "seismic category 1", which means that they should be designed to withstand vibrations as defined by "seismic level 2" - the most stringent seismic safety requirements for a NPP.

Table 4. Performances of selected scintillators and critical parameters for a nuclear reactor monitoring system.

\begin{tabular}{|c|c|c|c|c|c|c|}
\hline Crystal & $\begin{array}{c}\text { Light Yield } \\
\text { (Photons/MeV) }\end{array}$ & $\begin{array}{c}\text { Relative Light } \\
\text { Output }{ }^{1} \text { at } \\
\text { Radiation Dose (\%) }\end{array}$ & $\begin{array}{l}\text { Maximum } \\
\text { Temperature }\end{array}$ & $\begin{array}{c}\text { Thermal } \\
\text { Annealing Effect }\end{array}$ & Hygroscopicity & Ref \\
\hline LYSO & 33,200 & $73 \%$ at $383 \mathrm{Mrad}$ & $150^{\circ} \mathrm{C}$ & $\begin{array}{l}\text { Full recovery } \\
\left.\text { (above } 400^{\circ} \mathrm{C}\right)\end{array}$ & Non-hygroscopic & {$[22,47,58]$} \\
\hline Pr:LuAG & 24,000 & $36 \%$ at $382 \mathrm{Mrad}$ & $225^{\circ} \mathrm{C}$ & $\begin{array}{l}\text { Partial recovery } \\
\text { (above } 400^{\circ} \mathrm{C} \text { ) }\end{array}$ & Non-hygroscopic & {$[22,65]$} \\
\hline Ce:GPS & 30,000 & $15 \%$ at $369 \mathrm{Mrad}$ & $350^{\circ} \mathrm{C}$ & $\begin{array}{l}\text { Full recovery } \\
\text { (above } 400^{\circ} \mathrm{C} \text { ) }\end{array}$ & Non-hygroscopic & {$[22,35,66]$} \\
\hline
\end{tabular}

${ }^{1}$ Compared with the radiation undamaged scintillator. 
A study reported the temperature dependence and radiation resistance of several inorganic scintillators under severe NPP accident conditions (Table 3). In the study, the temperature dependence, radiation resistance, and radiation damage recovery via thermal annealing were investigated for Pr:LuAG, LYSO, and Ce:GPS scintillators [22], and all of these three scintillators are non-hygroscopic. The Ce:GPS scintillator showed about $15 \%$ light output of its original value (decrease of $85 \%$ ) after 369-Mrad gamma-ray irradiation; the Pr:LuAG and LYSO scintillators showed light outputs of 36\% and 73\%, respectively, after 380-Mrad gamma-ray irradiation. Therefore, of these scintillators, LYSO exhibited the strongest radiation resistance, and Ce:GPS exhibited the weakest radiation resistance. Moreover, in the temperature dependence evaluation of these scintillators, the maximum temperature at which the photopeak of a Cs-137 radiation source was observed (maximum observable photopeak temperature) for the Ce:GPS scintillator was $350{ }^{\circ} \mathrm{C}$, much higher than those of the Pr:LuAG and LYSO scintillators $\left(225^{\circ} \mathrm{C}\right.$ and $150{ }^{\circ} \mathrm{C}$, respectively). Particularly, Ce:GPS demonstrated almost consistent light output from RT up to approximately $250{ }^{\circ} \mathrm{C}$, and it showed rapid radiation damage recovery with more than $300^{\circ} \mathrm{C}$ thermal annealing. These properties of Ce:GPS revealed its potential to be employed under SA2 conditions ( $300{ }^{\circ} \mathrm{C}, 500 \mathrm{Mrad} / 6$ month) in a BWR NPP PCV, and SA3b conditions $\left(300^{\circ} \mathrm{C}, 200 \mathrm{Mrad} /\right.$ year $)$ in a PWR NPP CV.

\subsection{Space Exploration}

Gamma-ray spectroscopy (GRS) has been used in space exploration to study the composition of the surface of airless solar system bodies, such as the Moon, Mars, Mercury, and large S-class asteroids [67-69]. To perform GRS in space exploration, the gammaray detector should meet the criteria in terms of detection efficiency, energy resolution, and reliability. Since gamma-ray detectors used in space exploration are often exposed to high radiation environments arising from sources, such as galactic cosmic rays and solar flares, the radiation resistance of scintillators is crucial to ensure their reliability.

For example, the BepiColombo mission was a joint mission held by the European Space Agency and Japan Aerospace Exploration Agency to perform remote GRS of Mercury's surface and determine the elemental composition of the planet [70]. According to a study conducted to search for alternatives to traditional scintillators for space GRS [71], an ideal detector should possess the following properties-8-cm minimum gamma-ray pathlength, $>5-\mathrm{g} / \mathrm{cm}^{3}$ high density, excellent energy resolution of $\leq 3 \%$ for $662 \mathrm{keV}$ gamma radiation, and peak detection efficiency of $>6 \%$ at $6 \mathrm{MeV}$. In addition, it has to be proton radiation resistant to the 100-krad level.

Traditional scintillators, such as NaI:Tl and CsI:Tl, had insufficient energy resolution for the accurate distinction of the formation ions. Therefore, the demand for higher energy resolution, light yield, and radiation-resistant properties motivated researchers to search for alternative scintillators. A study that investigated the $\mathrm{LaBr}_{3}$ :Ce scintillator for the BepiColombo mission found that $\mathrm{LaBr}_{3}$ doped with $5 \%$ cerium concentration $\left(\mathrm{LaBr}_{3}: 5 \% \mathrm{Ce}\right)$ showed stable performance in its light yield and energy resolution against a high proton radiation environment $\left(100 \mathrm{MeV}\right.$ with a fluence of $10^{12}$ protons $/ \mathrm{cm}^{2}$ ) [72-74]. However, despite its excellent energy resolution and proton radiation-resistant properties, $\mathrm{LaBr}_{3}$ :Ce had the drawback of being intrinsically radioactive $\left(\sim 1 \mathrm{~Bq} \mathrm{~cm}^{-3}\right)$ due to the presence of ${ }^{138} \mathrm{La}$ [74]. To reduce this background noise, the Ce-doping concentration was increased until it completely replaced the lanthanum atom in $\mathrm{LaBr}_{3}$ : $\mathrm{Ce}$ to yield $\mathrm{CeBr}_{3}$, which mitigated the internal activity of $\mathrm{LaBr}_{3}: \mathrm{Ce}$ by around a factor of 30 at the cost of reduced energy resolution. $\mathrm{Up}$ to the energy level of $3 \mathrm{MeV}, \mathrm{CeBr}_{3}$ had better minimum detection limits than $\mathrm{LaBr}_{3}: \mathrm{Ce}$, and both scintillators proved to have much greater detection limits than high purity germanium semiconductor detectors. In addition, $\mathrm{CeBr}_{3}$, showed degradation from a gamma dose of $100 \mathrm{krad}$ and was more gamma-ray radiation-resistant than $\mathrm{LaBr}_{3}: 5 \% \mathrm{Ce}$ [75] but not significantly different in proton radiation hardness [76]. With respect to thermal dependence, $\mathrm{LaBr}_{3}: \mathrm{Ce}$ was shown to be more stable than that of $\mathrm{CeBr}_{3}$ [77]. 
The gamma large array space telescope (GLAST) calorimeter, operated at low earth orbit (600 km above the surface of the Earth) can provide information on the energy of electromagnetic showers through pair conversion reactions from gamma rays interaction in the tracker. Therefore, the calorimeter can measure energy and provide directional information for gamma rays ranging from $10 \mathrm{MeV}-300 \mathrm{GeV}$ [78]. Thus, scintillators should measure the wide range of energy; they should also be cost-effective and easier to grow in large sizes or long lengths. In addition, the scintillators should be resistant to the radiation environment, especially protons. At that altitude, $\mathrm{LaBr}_{3}$ :Ce could also be used for $\mathrm{LEO}$ missions $[79,80]$. Proton doses accumulated up to 5 years did not cause huge radiation damage to $\mathrm{LaBr}_{3}$ and $\mathrm{LaCl}_{3}$, with an acceptable amount of activation [80,81].

CsI:Tl for the Fermi Gamma-ray Space Telescope calorimeter calorimeter was reported to be one of the most common scintillators for calorimeters in space [82]. In a study on radiation resistance of CsI:Tl, CsI:Tl crystal's light yield tended to decrease rapidly to the first 20 Gy level. Specifically, tests with gamma rays and protons recorded $(24 \pm 4) \%$ and $(22 \pm 5) \%$ light yield decreases at 180 and 175 Gy doses, respectively. These records passed the quality assurance tests to be used for space calorimeters by having the dose of 10 and $10^{4}$ times higher than the ones seen in the orbit environment. Notably, the damages or displacements of the crystals due to gamma-ray irradiation could be partly recovered via thermal annealing, but not for proton irradiation [83]. In addition, 96 crystals of CsI were tested for their thermal stabilities showing no degradations in performance between $-30{ }^{\circ} \mathrm{C}$ to $50^{\circ} \mathrm{C}$, and the mechanical stabilities (primary fundamental mechanical frequency of $\sim 180 \mathrm{~Hz}$ ) surpassed the $100 \mathrm{~Hz}$ vibration requirement that occurs during launch [84]. CsI were treated with wrappings around crystal to withstand the different expansion due to different thermal coefficients, and a series of mechanical tests were conducted to qualify for the mission environments [85].

The Dark Matter Particle Explorer (DAMPE) experiment was launched in 2015, while the High Energy Cosmic Radiation Detection (HERD) experiment is planned to be installed on the Chinese Space Station. Utilizing the CALOCUBE electromagnetic calorimeter [86], DAMPE detects electrons and photons in the $5 \mathrm{GeV}-10 \mathrm{TeV}$ energy range for clues regarding dark matter and the origin of high energy cosmic rays [87,88], with an energy resolution of $1.5 \%$ at $800 \mathrm{GeV}$ in space [89]. For this mission, they use the crisscross structure that consists of long plastic scintillator logs with two photomultiplier tubes attached to the ends. In addition, a BGO calorimeter suppresses back-splash fake events [90]. The plastic scintillator efficiently measures the particle charge and discriminate photons and electrons while BGO is utilized for the discrimination between electrons and protons from the electron and hadron showers with the help of neutron detectors rejecting protons in background.

The DAMPE satellite, in orbit for several years during the mission, is designed to be resistant against a total dose of $20 \mathrm{krad}$ [91] and exposure to temperature ranges of $-20{ }^{\circ} \mathrm{C}$ to $+45^{\circ} \mathrm{C}$ when in storage and $-10{ }^{\circ} \mathrm{C}$ to $+30{ }^{\circ} \mathrm{C}$ when in operation [90]. For use in the mission, radiation detector modules have been first put through the modal analysis to evaluate its resistance against deformations and stress, and recorded $128.4 \mathrm{~Hz}$ more than the required first order modal frequency of $70 \mathrm{~Hz}$. In addition, to withstand the vibrational conditions during the mission, at least $1.24 \mathrm{~mm}, 6 \mathrm{~g}$ max (sweeping speed of $4 \mathrm{oct} / \mathrm{min}$ of $5-8 \mathrm{~Hz}$ and $8-100 \mathrm{~Hz}$ ), $0.05 \mathrm{~g}^{2} / \mathrm{Hz}$ and $6.41 \mathrm{Grms}$ (Duration $1 \mathrm{~min}, 20-100 \mathrm{~Hz}$, $100-600 \mathrm{~Hz}$, and $600-2000 \mathrm{~Hz}$ ) were needed for the sinusoidal and random tests according to the acceptable level criteria [90].

With regards to radiation hardness, BGO's afterglow increased only by around $7 \%$ up to $100 \mathrm{krad}$ dose, compared to the $9200 \%$ increase in afterglow for GAGG:Ce [92]. The BGO scintillator responds to energies ranging from $10 \mathrm{MeV}$ to $2 \mathrm{TeV}$ and reported a temperature dependent light output change of $-1.2 \%$ per degree Celsius around $0{ }^{\circ} \mathrm{C}$ [91], and $-2.2 \%$ per degree Celsius in the ATIC experiment [93]. Because of this temperature dependence, four faces of the satellite are protected by thermal insulation foils and orbits synchronously with a single radiating surface to mitigate temperature fluctuations [90]. A temperature variation of $50{ }^{\circ} \mathrm{C}$ in space causes $4 \mathrm{~mm}$ change in the detector modules' lengths due to the 
difference in thermal coefficients of honeycombs as protectors and scintillators. Therefore, special chips in the middle and the U-shape clamp are applied to reduce the frictions.

Recently, a relatively new scintillator, GAGG:Ce [94], has been reported to be a potential candidate for the LEO mission. Because of the high density $\left(6.63 \mathrm{~g} / \mathrm{cm}^{3}\right)$, nonhygroscopicity, high light yield (56,000 photon/MeV), and good energy resolution-all of which are superior to those of CsI:Tl-applications of GAGG:Ce have been investigated. However, the drawback of high afterglow after long exposure to proton environments has been observed. To mitigate this proton activation phenomenon, $\mathrm{Mg}$ co-doping has been employed [92]. A list of suitable scintillators for space applications, along with their main characteristics with focus on radiation tolerances, is presented in Table 5.

Table 5. Performances of reported scintillators and critical parameters for space exploration.

\begin{tabular}{|c|c|c|c|c|c|}
\hline Crystal & $\begin{array}{c}\text { Decay } \\
\text { Time (ns) }\end{array}$ & $\begin{array}{l}\text { Density } \\
\left(\mathrm{g} / \mathrm{cm}^{3}\right)\end{array}$ & $\begin{array}{c}\text { Relative Light Output }{ }^{1} \text { at } \\
\text { Radiation Dose (\%) for Proton }\end{array}$ & $\begin{array}{c}\text { Relative Light Output }{ }^{1} \text { at } \\
\text { Radiation Dose (\%) for Gamma-Ray }\end{array}$ & Ref \\
\hline CsI:Tl & 680 & 4.51 & $78 \%$ at $18 \mathrm{krad}$ & $30-80 \%$ at $100 \mathrm{krad}$ & {$[83,92]$} \\
\hline GAGG:Ce & 100 & 6.63 & $88 \%$ at $100 \mathrm{krad}$ & $90 \%$ at $100 \mathrm{krad}$ & {$[92,95]$} \\
\hline $\mathrm{LaBr}_{3}: \mathrm{Ce}$ & 15.0 & 5.07 & $100 \%$ at $1 \mathrm{Mrad}$ (No degradation) & $92 \%$ at $100 \mathrm{krad}$ & {$[20,73,96]$} \\
\hline $\mathrm{CeBr}_{3}$ & 18.7 & 5.18 & $100 \%$ at 1 Mrad(No degradation) & $98.6 \%$ at $100 \mathrm{krad}$ & {$[75,96]$} \\
\hline $\mathrm{BGO}$ & 300 & 7.1 & $\sim 80 \%$ at $1.2 \mathrm{Mrad}$ & $65-90 \%$ at $100 \mathrm{krad}$ & {$[97,98]$} \\
\hline
\end{tabular}

${ }^{1}$ Compared with the radiation undamaged scintillator.

\subsection{Other Applications}

\subsubsection{Nuclear Fusion Research}

Nuclear fusion occurs when two or more atomic nuclei combine under enormous pressure and temperature to form heavier atomic nuclei and release large amounts of energy in the process. The reaction between deuterium and tritium (D-T) is the most preferred among nuclear fusion reactions. To obtain a productive reaction of $\mathrm{D}-\mathrm{T}$ plasma, the temperature must be $150{ }^{\circ} \mathrm{C}-2.0 \times 10^{8}{ }^{\circ} \mathrm{C}$ to produce total energy of $17.6 \mathrm{MeV}$ per fusion, which is then converted into heat and finally converted into electricity through conventional methods [99]. During nuclear fusion, neutrons are produced by the main fusion reaction, $\mathrm{d}+\mathrm{t} \rightarrow \alpha+\mathrm{n}$. Here, the alpha particle heats the fusion-inducing plasma required for the $\mathrm{D}-\mathrm{T}$ reaction. However, in plasma fusion devices, various mechanisms (immediate loss, Coulomb collision, and magnetohydrodynamic activity) can lead to a loss of ions ( $\alpha$-particles, deuterium ions, and protons) in a phenomenon known as fast-ion loss, which reduces the alpha particle heating efficiency and performance of fusion reaction [100]. Scintillator-based fast-ion loss detectors (FILDs) are mainly used to directly detect charged particles to obtain information on interactions that cause rapid ion loss in self-fusion reactors [101,102]. Scintillator characteristics for FILDs require are short decay time (fast response) to efficiently detect the frequency of the magnetohydrodynamic fluctuations in fusion plasma, radiation resistance, and temperature resistance. However, the absolute measurement data of the escaping ions, available at RT, are not readily available at higher temperatures, although the detector response varies with temperature and radiation exposure [103]. Therefore, it is paramount to develop detectors that can survive high-radiation fluences and high-temperature environment around plasma fusion reactors [104].

$\mathrm{LaBr}_{3}(\mathrm{Ce})$ - a suitable choice to meet these requirements-has a fast scintillation time, high light yield, and high resistance to neutron damage. Besides, in fusion devices, the detector measures in a harsh environment at high neutron fluxes [105]. $\mathrm{LaBr}_{3}(\mathrm{Ce})$ has a $\sim 70 \%$ light output at $175{ }^{\circ} \mathrm{C}, 16$-ns short decay time [28], and strong radiation resistance [106].

Another scintillator- $\mathrm{Lu}_{2} \mathrm{SiO}_{5}: \mathrm{Ce}(\mathrm{LSO}: \mathrm{Ce})$ - is commonly regarded as efficient; however, it has a high cost compared with $(\mathrm{Lu}, \mathrm{Y})_{2} \mathrm{SiO}_{5}$ :Ce(LYSO:Ce). In addition, a 40-ns decay time showed that the light yield of the LYSO was approximately four times higher than that of the BGO. Therefore, $(\mathrm{Lu}, \mathrm{Y})_{2} \mathrm{SiO}_{5}: \mathrm{Ce}(\mathrm{LYSO}: \mathrm{Ce})$ has an advantage for the remote detection of gamma rays because of its high light output, high density, fast decay time with 
good radiation hardness, non-hygroscopic with high effective atomic numbers, and stable physical and chemical properties [107].

\subsubsection{Proton Therapy}

Proton therapy is effective in treating tumors, as it can deliver very accurate doses to tumors while reducing radiation exposure to normal tissues, as opposed to photon beam radiotherapy. Based on a proton beam's ability to concentrate on a specific region, precise quality control $(\mathrm{QC})$ of the equipment and treatment dose monitoring is crucial. However, the uncertainty of proton range, interorgan motion, etc., make precise cancer treatment challenging, even today [108]. Scintillation crystals can be applied in direct monitoring of the primary proton beam (in-beam monitoring), or indirect monitoring of the proton beam for radiation beam QC and treatment dose verification [109,110].

Direct monitoring detectors are exposed to the primary proton beam. In a study that assessed radiation damage to radiation detectors for direct monitoring of proton therapy systems, the thin YAG:Ce scintillator showed a 50\% decrease in the signal efficiency (defined as the ratio of responses of damaged to undamaged scintillator) at around $3.1 \mathrm{MeV}$ proton fluence of $(1-2) \times 10^{16} \mathrm{~cm}^{-2}$. This value is a two-order greater radiation resistance than those of position-sensitive silicon and diamond radiation detectors [111].

Contrary to direct detection of the proton beam, in vivo patient dose verification can be performed using secondary gamma radiation photons created by the primary proton beam in a system [112]. This gamma emission process has been reported to be correlated with the patient dose and might provide real-time in vivo patient dose information to significantly improve treatment accuracy. The gamma photons of interest-varying from $511 \mathrm{keV}$ for in-beam position emission tomography and up to several $\mathrm{MeV}$ for prompt gamma-require the use of thick, bright, and fast response inorganic scintillation crystals of high stopping power. However, in addition to gamma photons, large numbers of highly energetic secondary neutron particles are emitted, which can damage the radiation detector if one is placed close to the patient (e.g., inline system). It has been estimated that a prompt gamma detector placed vertically at a distance of $30 \mathrm{~cm}$ from a $200-\mathrm{MeV}$ proton beam is hit by $2 \times 10^{-5}$ neutrons $/ \mathrm{cm}^{2} /$ stopped proton [113]. In summary, assuming 380 patients/yr, the dose-verified detector should withstand at least fluences of $10^{11}$ neutrons $/ \mathrm{cm}^{2}$ to operate without degradation for at least $5 \mathrm{yr}$ [114]. Possible detector performance degradation due to these secondary neutrons, despite being a topic of relatively small interest, should not be overlooked when selecting scintillation crystals for proton therapy monitoring systems.

\section{Conclusions}

In this article, we reviewed the effects of high temperature and radiation environments on scintillation crystals, as well as the environmental conditions that scintillator-based radiation detectors are exposed to according to their application fields. The environmental conditions required for scintillation in many application fields are expected to be harsher in the future. For example, in the well-logging industry, wells need to be drilled deeper to gain access to new fuel sources. In future HEP experiments, the radiation dose to the calorimeter is expected to significantly increase. For example, in the Mu2e-II experiment, the event rate, and thus the radiation dose, are predicted to increase by a factor of ten compared to the Mu2e-I experiment. Finally, space explorations are getting more distant and last for longer durations, exposing components, including scintillators, to more radiation. In some applications fields, such as well-logging industry, space exploration and NPP, factors such as vibration and humidity, in addition to high temperature and high radiation, should also be accounted for. Other fields that could expose inorganic scintillation crystals to harsh conditions include nondestructive testing (NDT) of pipelines in oil and gas plants, marine explorations, radiation chemistry, etc. Factors outlined in this paper should be considered during the selection of scintillation crystal for these applications. Finally, although not 
within the scope of this paper, the effects of these extreme conditions on the photosensor such as the PMT should also be considered.

Critical parameters to be considered when selecting scintillators and their performances under the abovementioned extreme conditions have been summarized in this article. No single scintillator met all requirements for use in these extreme environments; tradeoffs are involved in scintillator performance. Thus, there is a need for various scintillators tailored to specific applications. In the past, the main research and use of scintillators in extreme environments were mainly limited to HEP, but applications are expanding to reactor monitoring systems, marine and space exploration, nuclear fusion, radiation therapy, etc. Therefore, the R\&D of inorganic scintillation crystals resistant to extreme conditions will continue.

Author Contributions: Conceptualization, C.K., C.P. and J.-Y.Y.; Methodology, C.K., W.L., C.P. and J.-Y.Y.; Validation, C.K., W.L., A.M., A.E., K.L., C.P. and J.-Y.Y.; Investigation, C.K., W.L., A.M. and A.E.; Data curation, C.K., W.L., A.M. and A.E.; Writing—original draft preparation, C.K.; Writing-review and editing, K.L., C.P. and J.-Y.Y.; Visualization, C.K., W.L.; Supervision, K.L., C.P. and J.-Y.Y.; Project administration, C.P. and J.-Y.Y.; Funding acquisition, J.-Y.Y. All authors have read and agreed to the published version of the manuscript.

Funding: This work was supported by the National Research Foundation of Korea (NRF-2017M2A8A4017932， NRF-2020R111A1A01070761， NRF-2020R1A2C2007376 and NRF-2020M2A8A4023713).

Conflicts of Interest: The authors declare no conflict of interest.

\section{References}

1. Knoll, G.F. Radiation Detection and Measurement; John Wiley \& Sons: Hoboken, NJ, USA, 2010; ISBN 0470131489.

2. Kim, C.; Yeom, J.-Y.; Kim, G. Digital n- $\gamma$ Pulse Shape Discrimination in Organic Scintillators with a High-Speed Digitizer. J. Radiat. Prot. Res. 2019, 44, 53-63. [CrossRef]

3. Saatsakis, G.; Ninos, K.; Valais, I.; Martini, N.; Kalyvas, N.; Kantsos, C.; Bakas, A.; Kandarakis, I.; Panayiotakis, G.; Michail, C. Luminescence efficiency of $\mathrm{CaF}_{2}$ : Eu single crystals: Temperature dependence. Procedia Struct. Integr. 2020, 26, 3-10. [CrossRef]

4. Park, C.; Kim, C.; Kim, J.; Lee, Y.; Na, Y.; Lee, K.; Yeom, J.Y. Performance comparison between ceramic Ce:GAGG and single crystal Ce:GAGG with digital-SiPM. J. Instrum. 2017, 12. [CrossRef]

5. Cherepy, N.J.; Kuntz, J.D.; Roberts, J.J.; Hurst, T.A.; Drury, O.B.; Sanner, R.D.; Tillotson, T.M.; Payne, S.A. Transparent ceramic scintillator fabrication, properties, and applications. In Proceedings of the Hard X-Ray, Gamma-Ray, and Neutron Detector Physics X, International Society for Optics and Photonics, San Diego, CA, USA, 4 September 2008; Volume 7079, p. 70790X.

6. Pidol, L.; Kahn-Harari, A.; Viana, B.; Virey, E.; Ferrand, B.; Dorenbos, P.; De Haas, J.T.M.; Van Eijk, C.W.E. High efficiency of lutetium silicate scintillators, Ce-doped LPS, and LYSO crystals. IEEE Trans. Nucl. Sci. 2004, 51, 1084-1087. [CrossRef]

7. Lin, Y.C.; Bettinelli, M.; Karlsson, M. Unraveling the Mechanisms of Thermal Quenching of Luminescence in Ce ${ }^{3+}$-Doped Garnet Phosphors. Chem. Mater. 2019, 31, 3851-3862. [CrossRef]

8. Struck, C.W.; Fonger, W.H. Unified model of the temperature quenching of narrow-line and broad-band emissions. J. Lumin. 1975, 10. [CrossRef]

9. Struck, C.W.; Fonger, W.H. Understanding Luminescence Spectra and Efficiency Using Wp and Related Functions; Springer Science \& Business Media: Berlin/Heidelberg, Germany, 2012; Volume 13, ISBN 3642486290.

10. Bleijenberg, K.C.; Blasse, G. QMSCC calculations on thermal quenching of model phosphor systems. J. Solid State Chem. 1979, 28. [CrossRef]

11. Wang, Y.; Chen, B.; Wang, F. Overcoming thermal quenching in upconversion nanoparticles. Nanoscale 2021. [CrossRef]

12. Witkowski, D.; Rothamer, D.A. Emission properties and temperature quenching mechanisms of rare-earth elements doped in garnet hosts. J. Lumin. 2017, 192. [CrossRef]

13. Ueda, J.; Tanabe, S.; Nakanishi, T. Analysis of $\mathrm{Ce}^{3+}$ luminescence quenching in solid solutions between $\mathrm{Y}_{3} \mathrm{Al}_{5} \mathrm{O}_{12}$ and $\mathrm{Y}_{3} \mathrm{Ga}_{5} \mathrm{O}_{12}$ by temperature dependence of photoconductivity measurement. J. Appl. Phys. 2011, 110, 053102. [CrossRef] [PubMed]

14. Di Bartolo, B. Advances in Nonradiative Processes in Solids; Springer Science \& Business Media: Berlin/Heidelberg, Germany, 2013; Volume 249, ISBN 1475744463.

15. Dorenbos, P. Electronic structure and optical properties of the lanthanide activated $\mathrm{RE}_{3}\left(\mathrm{Al}_{1-\mathrm{x}} \mathrm{Ga}_{\mathrm{x}}\right)_{5} \mathrm{O}_{12}(\mathrm{RE}=\mathrm{Gd}, \mathrm{Y}, \mathrm{Lu})$ garnet compounds. J. Lumin. 2013, 134. [CrossRef]

16. Zhu, R.Y. Radiation damage in scintillating crystals. Nucl. Instrum. Methods Phys. Res. Sect. A Accel. Spectrometers Detect. Assoc. Equip. 1998, 413, 297-311. [CrossRef]

17. Zhu, R.-Y. Radiation Damage Effects BT. In Handbook of Particle Detection and Imaging; Grupen, C., Buvat, I., Eds.; Springer: Berlin/Heidelberg, Germany, 2012; pp. 535-555. ISBN 978-3-642-13271-1. 
18. Viret, S.; Group, L.P.C.A. LASER monitoring system for the ATLAS Tile Calorimeter. Nucl. Instrum. Methods Phys. Res. Sect. A Accel. Spectrometers Detect. Assoc. Equip. 2010, 617, 120-122. [CrossRef]

19. Marjanović, M. ATLAS Tile calorimeter calibration and monitoring systems. IEEE Trans. Nucl. Sci. 2019, 66, 1228-1235. [CrossRef]

20. Drozdowski, W.; Dorenbos, P.; Bos, A.J.; Kraft, S.; Buis, E.J.; Maddox, E.; Owens, A.; Quarati, F.G.; Dathy, C.; Ouspenski, V. Gamma-Ray Induced Radiation Damage in $\mathrm{LaBr}_{3}: 5 \% \mathrm{Ce}$ and $\mathrm{LaCl}_{3}: 10 \%$ Ce Scintillators. IEEE Trans. Nucl. Sci. 2007, 54, 1387-1391. [CrossRef]

21. Lederer, S.; Akhmadaliev, S.; Forck, P.; Gütlich, E.; Lieberwirth, A.; Ensinger, W. Thermal annealing behavior of $\alpha-\mathrm{Al}_{2} \mathrm{O}_{3}$ scintillation screens. Nucl. Instruments Methods Phys. Res. Sect. B Beam Interact. Mater. Atoms 2015, 365, 548-552. [CrossRef]

22. Kim, C.; Kim, D.D.; Lee, Y.; Park, C.; Ullah, M.N.; Kim, D.D.; Kwon, I.; Hur, S.; Yeom, J.-Y. Radiation resistance and temperature dependence of Ce:GPS scintillation crystal. Radiat. Phys. Chem. 2021, 183, 109396. [CrossRef]

23. Nikitin, A.; Bliven, S. Needs of well logging industry in new nuclear detectors. In Proceedings of the IEEE Nuclear Science Symposuim \& Medical Imaging Conference, Knoxville, Tennessee, 30 Otober-6 November 2010; pp. 1214-1219.

24. Melcher, C.L. Scintillators for well logging applications. Nucl. Inst. Methods Phys. Res. B 1989, 40-41. [CrossRef]

25. Rozsa, C.; Dayton, R.; Raby, P.; Kusner, M.; Schreiner, R. Characteristics of scintillators for well logging to $225^{\circ} \mathrm{C}$. IEEE Trans. Nucl. Sci. 1990, 37. [CrossRef]

26. Melcher, C.L.; Schweitzer, J.S.; Manente, R.A.; Peterson, C.A. Applications of single crystals in oil well logging. J. Cryst. Growth 1991, 109. [CrossRef]

27. Bizarri, G.; De Haas, J.T.M.; Dorenbos, P.; Van Eijk, C.W.E. First time measurement of gamma-ray excited $\mathrm{LaBr}_{3}: 5 \% \mathrm{Ce}^{3+}$ and $\mathrm{LaCl}_{3}: 10 \% \mathrm{Ce}^{3+}$ temperature dependent properties. Phys. Status Solidi 2006, 203, R41-R43. [CrossRef]

28. Hou, Y.; Liu, S.; Yuan, H.; Gui, Q.; Zhang, C.; Fang, Z.; Zhang, M. Study on High-Temperature Performance of LaBr $3(\mathrm{Ce})$ Scintillators. In Proceedings of the IOP Conference Series: Materials Science and Engineering, Kazimierz Dolny, Poland, 21-23 November 2019; Volume 678.

29. Findley, K.O.; Johnson, J.; Bahr, D.F.; Doty, F.P.; Frey, J. Fracture and deformation behavior of common and novel scintillating single crystals. In Proceedings of the Penetrating Radiation Systems and Applications VIII, International Society for Optics and Photonics, San Diego, CA, USA, 29-30 August 2007; Volume 6707, p. 670706.

30. Menge, P.R.; Richaud, D. Behavior of $\mathrm{Cs}_{2} \mathrm{LiYCl}_{6}$ :Ce scintillator up to $175{ }^{\circ} \mathrm{C}$. In Proceedings of the IEEE Nuclear Science Symposium Conference Record, Valencia, Spain, 23-29 October 2011.

31. Berheide, M.; Roscoe, B.A.; Qian, J.; Spillane, T.; Shestakova, I.; Philip, O.G.; Vajda, S. Elpasolite Scintillator-Based Neutron Detector for Oilfield Applications. U.S. Patent Application 14/352,968, 30 October 2014.

32. Melcher, C.L.; Schweitzei, J.S.; Manente, R.A.; Peterson, C.A. Applicability of Gso Scintillators for Well Logging. IEEE Trans. Nucl. Sci. 1991, 38. [CrossRef]

33. Takeda, T.; Miyata, T.; Muramatsu, F.; Tomiki, T. Fast Decay UV Phosphor-YAlO 3 : Ce. J. Electrochem. Soc. 1980, 127, 438-444. [CrossRef]

34. Yanagida, T.; Fujimoto, Y.; Kurosawa, S.; Kamada, K.; Takahashi, H.; Fukazawa, Y.; Nikl, M.; Chani, V. Temperature Dependence of Scintillation Properties of Bright Oxide Scintillators for Well-Logging. Jpn. J. Appl. Phys. 2013, 52, 076401. [CrossRef]

35. Kawamura, S.; Kaneko, J.H.; Higuchi, M.; Yamaguchi, T.; Haruna, J.; Yagi, Y.; Susa, K.; Fujita, F.; Homma, A.; Nishiyama, S.; et al. Floating zone growth and scintillation characteristics of cerium-doped gadolinium pyrosilicate single crystals. IEEE Trans. Nucl. Sci. 2007, 54, 1383-1386. [CrossRef]

36. Boatner, L.A.; Neal, J.S.; Kolopus, J.A.; Ramey, J.O.; Akkurt, H. The characterization of scintillator performance at temperatures up to 400 degrees centigrade. Nucl. Instrum. Methods Phys. Res. Sect. A Accel. Spectrometers Detect. Assoc. Equip. 2013, 709. [CrossRef]

37. Kerek, A.; Klamra, W.; Norlin, L.O.; Novák, D.; Westman, S.; Lidberg, J.; Mannervik, S.; The CRYRING Staff. Fast Inorganic Scintillators for Beam Diagnostics at Extreme High Vacuum. In Proceedings of the EPAC, Stockholm, Sweden, $22-26$ June 1998.

38. Doty, F.P.; Yang, P.; Zhou, X.W. Development of Atomistic Models to Aid the Design of New Scintillator Materials; Sandia National Laboratories: Albuquerque, NM, USA, 2010.

39. McGregor, D.S. Materials for gamma-ray spectrometers: Inorganic scintillators. Annu. Rev. Mater. Res. 2018, 48, $245-277$. [CrossRef]

40. Del Guerra, A.; De Notaristefani, F.; Di Domenico, G.; Pani, R.; Zavattini, G. Measurement of absolute light yield and determination of a lower limit for the light attenuation length for YAP:Ce crystal. IEEE Trans. Nucl. Sci. 1997, 44, 2415-2418. [CrossRef]

41. Drozdowski, W.; Wojtowicz, A.J.; Tadeusz, Ł. Scintillation properties of LuAP and LuYAP crystals activated with Cerium and Molybdenum. Nucl. Instrum. Methods Phys. Res. Sect. A Accel. Spectrometers Detect. Assoc. Equip. 2006, 562, 254-261. [CrossRef]

42. Zhu, R.-Y. The Next Generation of Crystal Detectors. J. Phys. Conf. Ser. 2015, 587, 012055. [CrossRef]

43. Chatrchyan, S.; Khachatryan, V.; Sirunyan, A.M.; Tumasyan, A.; Adam, W.; Aguilo, E.; Bergauer, T.; Dragicevic, M.; Erö, J.; Fabjan, C.; et al. Observation of a new boson at a mass of $125 \mathrm{GeV}$ with the CMS experiment at the LHC. Phys. Lett. Sect. B Nucl. Elem. Part High-Energy Phys. 2012, 716. [CrossRef]

44. Tabarelli De Fatis, T. Role of the CMS electromagnetic calorimeter in the hunt for the Higgs boson in the two-gamma channel. J. Phys. Conf. Ser. 2012, 404, 012002. [CrossRef]

45. Zhu, R.Y. Ultrafast and Radiation Hard Inorganic Scintillators for Future HEP Experiments. J. Phys. Conf. Ser. 2019, 1162, 012022. [CrossRef]

46. Wei, Z.Y.; Zhu, R.Y. A study on undoped CsI crystals. Nucl. Inst. Methods Phys. Res. A 1993, 326. [CrossRef] 
47. Yang, F.; Zhang, L.; Zhu, R.Y. Gamma-Ray Induced Radiation Damage Up to 340 Mrad in Various Scintillation Crystals. IEEE Trans. Nucl. Sci. 2016, 63. [CrossRef]

48. Prasad, V. Performance of the cesium iodide calorimeter at the KTeV experiment at Fermilab. Nucl. Instrum. Methods Phys. Res. Sect. A Accel. Spectrometers Detect. Assoc. Equip. 2001, 461, 341-343. [CrossRef]

49. Zhu, R.Y.; Stone, H.; Newman, H.; Zhou, T.Q.; Tan, H.R.; He, C.F. A study on radiation damage in doped BGO crystals. Nucl. Inst. Methods Phys. Res. A 1991, 302. [CrossRef]

50. Zhu, R.Y.; Ma, D.A.; Newman, H.B.; Woody, C.L.; Kierstead, J.A.; Stoll, S.P.; Levy, P.W. A study on the properties of lead tungstate crystals. Nucl. Instrum. Methods Phys. Res. Sect. A Accel. Spectrometers Detect. Assoc. Equip. 1996, 376. [CrossRef]

51. Huhtinen, M.; Lecomte, P.; Luckey, D.; Nessi-Tedaldi, F.; Pauss, F. High-energy proton induced damage in $\mathrm{PbWO}_{4}$ calorimeter crystals. Nucl. Instrum. Methods Phys. Res. Sect. A Accel. Spectrometers Detect. Assoc. Equip. 2005, 545. [CrossRef]

52. Hu, C.; Yang, F.; Zhang, L.; Zhu, R.Y.; Kapustinsky, J.; Mocko, M.; Nelson, R.; Wang, Z. Neutron-Induced Radiation Damage in $\mathrm{BaF}_{2}$, LYSO/LFS and PWO Crystals. J. Phys. Conf. Ser. 2019, 1162, 012020. [CrossRef]

53. Zhang, L.; Mao, R.; Yang, F.; Zhu, R.Y. LSO/LYSO crystals for calorimeters in future HEP experiments. IEEE Trans. Nucl. Sci. 2014, 61. [CrossRef]

54. Eigen, G.; Zhou, Z.; Chao, D.; Cheng, C.H.; Echenard, B.; Flood, K.T.; Hitlin, D.G.; Porter, F.C.; Zhu, R.Y.; De Nardo, G.; et al. A LYSO calorimeter for the SuperB factory. Nucl. Instrum. Methods Phys. Res. Sect. A Accel. Spectrometers Detect. Assoc. Equip. 2013, 718. [CrossRef]

55. Pezzullo, G.; Budagov, J.; Carosi, R.; Cervelli, F.; Cheng, C.; Cordelli, M.; Corradi, G.; Davydov, Y.; Echenard, B.; Giovannella, S.; et al. The LYSO crystal calorimeter for the Mu2e experiment. J. Instrum. 2014, 9, C03018. [CrossRef]

56. Kobayashi, M.; Ishii, M. Excellent radiation-resistivity of cerium-doped gadolinium silicate scintillators. Nucl. Instrum. Methods Phys. Res. Sect. B Beam Interact. Mater. Atoms 1991, 61, 491-496. [CrossRef]

57. Tanaka, M.; Hara, K.; Kim, S.; Kondo, K.; Takano, H.; Kobayashi, M.; Ishibashi, H.; Kurashige, K.; Susa, K.; Ishii, M. Applications of cerium-doped gadolinium silicate $\mathrm{Gd}_{2} \mathrm{SiO}_{5}$ :Ce scintillator to calorimeters in high-radiation environment. Nucl. Instrum. Methods Phys. Res. Sect. A Accel. Spectrometers Detect. Assoc. Equip. 1998, 404, 283-294. [CrossRef]

58. Chen, J.; Mao, R.; Zhang, L.; Zhu, R. Gamma-ray induced radiation damage in large size LSO and LYSO crystal samples. IEEE Trans. Nucl. Sci. 2007, 54, 1319-1326. [CrossRef]

59. Derdzyan, M.V.; Ovanesyan, K.L.; Petrosyan, A.G.; Belsky, A.; Dujardin, C.; Pedrini, C.; Auffray, E.; Lecoq, P.; Lucchini, M.; Pauwels, K. Radiation hardness of LuAG: Ce and LuAG: Pr scintillator crystals. J. Cryst. Growth 2012, 361, 212-216. [CrossRef]

60. Zhu, R. On quality requirements to the barium fluoride crystals. Nucl. Instrum. Methods Phys. Res. Sect. A Accel. Spectrometers Detect. Assoc. Equip. 1994, 340, 442-457. [CrossRef]

61. International Atomic Energy Agency. Nuclear Power Reactors in the World. Ref. Data Ser. 2019, 2, 541-5678.

62. Accident Monitoring Systems for Nuclear Power Plants; International Atomic Energy Agency: Vienna, Austria, 2015. Available online: https: / / www.iaea.org/publications/10754/accident-monitoring-systems-for-nuclear-power-plants (accessed on 1 February 2021).

63. Murata, A.; Isoda, K.; Ikeuchi, T.; Matsui, T.; Shiraishi, F.; Oba, M. Classification method of severe accident condition for the development of severe accident instrumentation and monitoring system in nuclear power plant. J. Nucl. Sci. Technol. 2016, 53. [CrossRef]

64. Seismic Design and Qualification for Nuclear Power Plants; International Atomic Energy Agency: Vienna, Austria, 2003. Available online: https:/ / www.iaea.org/publications/6732/seismic-design-and-qualification-for-nuclear-power-plants (accessed on 24 May 2021).

65. Sreebunpeng, K.; Chewpraditkul, W.; Nikl, M. Light yield and light loss coefficient of LuAG: Ce and LuAG: Pr under excitation with $\alpha$-and $\gamma$-rays. J. Cryst. Growth 2017, 468, 373-375. [CrossRef]

66. Kaneko, J.H.; Izaki, K.; Toui, K.; Shimaoka, T.; Morishita, Y.; Tsubota, Y.; Higuchi, M. An alpha particle detector based on a GPS mosaic scintillator plate for continuous air monitoring in plutonium handling facilities. Radiat. Meas. 2016, 93, 13-19. [CrossRef]

67. Trombka, J.I.; Boynton, W.V.; Brückner, J.; Squyres, S.; Clark, P.E.; Starr, R.; Evans, L.G.; Floyd, S.R.; McClanahan, T.P.; Goldsten, J. Remote planetary geochemical exploration with the NEAR X-ray/gamma-ray spectrometer. Nucl. Instrum. Methods Phys. Res. Sect. A Accel. Spectrometers Detect. Assoc. Equip. 1999, 422, 572-576. [CrossRef]

68. Reedy, R.C.; Evans, L.G.; Brückner, J.; Kim, K.J.; Boynton, W. V Gamma rays in a spectrum from the Mars Odyssey gamma-ray spectrometer. In Proceedings of the Lunar and Planetary Science Conference, League City, TX, USA, 11-15 March 2002; p. 1592.

69. Harrington, T.M.; Marshall, J.H.; Arnold, J.R.; Peterson, L.E.; Trombka, J.I.; Metzger, A.E. The Apollo gamma-ray spectrometer. Nucl. Instrum. Methods 1974, 118, 401-411. [CrossRef]

70. Hansson, C.C.T.; Owens, A.; Shortt, B.; Dorenbos, P.; Quarati, F.; Williams, R.; Hahn, D.; Toepfer, T.; Pathier, L.; Schotanus, P.; et al. Development of low noise scintillator crystals for planetary space missions. In Proceedings of the IEEE Nuclear Science Symposium Conference Record, Anaheim, CA, USA, 29 October-3 November 2012; pp. 927-930.

71. Owens, A. Scintillators on interplanetary space missions. IEEE Trans. Nucl. Sci. 2008, 55, 1430-1436. [CrossRef]

72. Owens, A.; Bos, A.J.J.; Brandenburg, S.; Buis, E.J.; Dathy, C.; Dorenbos, P.; van Eijk, C.W.E.; Kraft, S.; Ostendorf, R.W.; Ouspenski, V.; et al. Assessment of the radiation tolerance of $\mathrm{LaBr}_{3}$ :Ce scintillators to solar proton events. Nucl. Instrum. Methods Phys. Res. Sect. A Accel. Spectrometers Detect. Assoc. Equip. 2007, 572, 785-793. [CrossRef] 
73. Drozdowski, W.; Dorenbos, P.; Bos, A.J.J.; De Haas, J.T.M.; Kraft, S.; Maddox, E.; Owens, A.; Quarati, F.G.A.; Dathy, C.; Ouspenski, V. Effect of proton dose, crystal size, and cerium concentration on scintillation yield and energy resolution of $\mathrm{LaBr}_{3}: \mathrm{Ce}$. IEEE Trans. Nucl. Sci. 2007, 54, 736-740. [CrossRef]

74. Kozyrev, A.; Mitrofanov, I.; Owens, A.; Quarati, F.; Benkhoff, J.; Bakhtin, B.; Fedosov, F.; Golovin, D.; Litvak, M.; Malakhov, A.; et al. A comparative study of $\mathrm{LaBr}_{3}\left(\mathrm{Ce}^{3+}\right)$ and $\mathrm{CeBr}_{3}$ based gamma-ray spectrometers for planetary remote sensing applications. Rev. Sci. Instrum. 2016, 87. [CrossRef]

75. Drozdowski, W.; Dorenbos, P.; Bos, A.J.J.; Bizarri, G.; Owens, A.; Quarati, F.G.A. CeBr 3 scintillator development for possible use in space missions. IEEE Trans. Nucl. Sci. 2008, 55, 1391-1396. [CrossRef]

76. Kraft, S.; Maddox, E.; Buis, E.J.; Owens, A.; Quarati, F.G.A.; Dorenbos, P.; Drozdowski, W.; Bos, A.J.J.; De Haas, J.T.M.; Brouwer, H.; et al. Development and characterization of large la-halide gamma-ray scintillators for future planetary missions. IEEE Trans. Nucl. Sci. 2007, 54, 873-878. [CrossRef]

77. Payne, S.A.; Hunter, S.; Ahle, L.; Cherepy, N.J.; Swanberg, E. Nonproportionality of scintillator detectors. III. Temperature dependence studies. IEEE Trans. Nucl. Sci. 2014, 61, 2771-2777. [CrossRef]

78. Johnson, W.N.; Grove, J.E. A CsI (T1) Hodoscopic Calorimeter for the GLAST Mission. In Proceedings of the 1997 IEEE Nuclear Science Symposium Conference Record, Albuquerque, NM, USA, 9-15 November 1997; pp. 1-5.

79. McConnell, M.L.; Bloser, P.F.; Legere, J.; Ryan, J.M. Applications for New Scintillator Technologies in Gamma Ray Astronomy. J. Phys. Conf. Ser. 2016, 763. [CrossRef]

80. Bloser, P.F.; McConnell, M.L.; Macri, J.R.; Bruillard, P.J.; Ryan, J.M.; Hajdas, W. Radiation damage and activation from proton irradiation of advanced scintillators. IEEE Nucl. Sci. Symp. Conf. Rec. 2006, 3, 1500-1505. [CrossRef]

81. Buis, E.-J.; Beijersbergen, M.; Kraft, S.; Owens, A.; Quarati, F.; Brandenburg, S.; Ostendorf, R. New scintillators for focal plane detectors in gamma-ray missions. In Focusing Telescopes in Nuclear Astrophysics; Springer: Berlin/Heidelberg, Germany, 2006; pp. 333-339.

82. Dujardin, C.; Auffray, E.; Bourret-Courchesne, E.; Dorenbos, P.; Lecoq, P.; Nikl, M.; Vasil’Ev, A.N.; Yoshikawa, A.; Zhu, R.Y. Needs, trends, and advances in inorganic scintillators. IEEE Trans. Nucl. Sci. 2018, 65, 1977-1997. [CrossRef]

83. Gavler, S.B.; Carius, S.; Carlson, P.; Johansson, G.; Klamra, W.; Pearce, M. Radiation tests of CsI(Tl) crystals for the GLAST satellite mission. Nucl. Instrum. Methods Phys. Res. Sect. A Accel. Spectrometers Detect. Assoc. Equip. 2005, 545, 842-851. [CrossRef]

84. Ampe, J.; Chekhtman, A.; Dizon, P.; Grove, J.E.; Johnson, W.N.; Leas, B.E.; Sandora, D.P.; Strickman, M.S. The calibration and environmental testing of the engineering module of GLAST CsI calorimeter. IEEE Trans. Nucl. Sci. 2004, 51, 2008-2011. [CrossRef]

85. Johnson, W.N.; Grove, J.E.; Phlips, B.F.; Ampe, J.; Singh, S.; Ponslet, E. The construction and performance of the CsI hodoscopic calorimeter for the GLAST beam test engineering module. IEEE Trans. Nucl. Sci. 2001, 48, 1182-1189. [CrossRef]

86. Vannuccini, E.; Adriani, O.; Agnesi, A.; Albergo, S.; Auditore, L.; Basti, A.; Berti, E.; Bigongiari, G.; Bonechi, L.; Bonechi, S.; et al. CaloCube: A new-concept calorimeter for the detection of high-energy cosmic rays in space. Nucl. Instrum. Methods Phys. Res. Sect. A Accel. Spectrometers Detect. Assoc. Equip. 2017, 845, 421-424. [CrossRef]

87. Chang, J.; Ambrosi, G.; An, Q.; Asfandiyarov, R.; Azzarello, P.; Bernardini, P.; Bertucci, B.; Cai, M.S.; Caragiulo, M.; Chen, D.Y.; et al. The DArk Matter Particle Explorer mission. Astropart. Phys. 2017, 95, 6-24. [CrossRef]

88. Azzarello, P.; Ambrosi, G.; Asfandiyarov, R.; Bernardini, P.; Bertucci, B.; Bolognini, A.; Cadoux, F.; Caprai, M.; De Mitri, I.; Domenjoz, M.; et al. The DAMPE silicon-tungsten tracker. Nucl. Instrum. Methods Phys. Res. Sect. A Accel. Spectrometers Detect. Assoc. Equip. 2016, 831, 378-384. [CrossRef]

89. Zhang, Z.; Wang, C.; Dong, J.; Wei, Y.; Wen, S.; Zhang, Y.; Li, Z.; Feng, C.; Gao, S.; Shen, Z.T.; et al. The calibration and electron energy reconstruction of the BGO ECAL of the DAMPE detector. Nucl. Instrum. Methods Phys. Res. Sect. A Accel. Spectrometers Detect. Assoc. Equip. 2016, 836, 98-104. [CrossRef]

90. Yu, Y.; Sun, Z.; Su, H.; Yang, Y.; Liu, J.; Kong, J.; Xiao, G.; Ma, X.; Zhou, Y.; Zhao, H.; et al. The plastic scintillator detector for DAMPE. Astropart. Phys. 2017, 94, 1-10. [CrossRef]

91. Wei, Y.; Zhang, Z.; Zhang, Y.; Wang, C.; Wen, S.; Dong, J.; Li, Z.; Wang, X.; Xu, Z.; Huang, G.; et al. Performance of the BGO Detector Element of the DAMPE Calorimeter. IEEE Trans. Nucl. Sci. 2016, 63, 548-551. [CrossRef]

92. Yoneyama, M.; Kataoka, J.; Arimoto, M.; Masuda, T.; Yoshino, M.; Kamada, K.; Yoshikawa, A.; Sato, H.; Usuki, Y. Evaluation of GAGG:Ce scintillators for future space applications. J. Instrum. 2018, 13. [CrossRef]

93. Isbert, J.; Adams, J.H.; Ahn, H.S.; Bashindzhagyan, G.L.; Batkov, K.E.; Christl, M.; Fazely, A.R.; Ganel, O.; Gunashingha, R.M.; Guzik, T.G.; et al. Temperature effects in the ATIC BGO calorimeter. Adv. Sp. Res. 2008, 42, 437-441. [CrossRef]

94. Yeom, J.Y.; Yamamoto, S.; Derenzo, S.E.; Spanoudaki, V.C.; Kamada, K.; Endo, T.; Levin, C.S. First performance results of Ce: GAGG scintillation crystals with silicon photomultipliers. IEEE Trans. Nucl. Sci. 2013, 60, 988-992. [CrossRef]

95. Kang, S.J.; Park, J.M.; Lee, J.Y.; Kim, H.L.; Son, J.K. Measurements of the scintillation properties and the radiation hardness of the GAGG single crystal. New Phys. Sae Mulli 2015, 65, 474-478. [CrossRef]

96. Quarati, F.G.A.; Dorenbos, P.; Van Der Biezen, J.; Owens, A.; Selle, M.; Parthier, L.; Schotanus, P. Scintillation and detection characteristics of high-sensitivity $\mathrm{CeBr}_{3}$ gamma-ray spectrometers. Nucl. Instrum. Methods Phys. Res. Sect. A Accel. Spectrometers Detect. Assoc. Equip. 2013, 729, 596-604. [CrossRef] 
97. Yang, F.; Zhang, L.; Zhu, R.-Y.; Kapustinsky, J.; Nelson, R.; Wang, Z. Proton-induced radiation damage in BGO, LFS, PWO and a LFS/W/Quartz capillary shashlik cell. In Proceedings of the 2016 IEEE Nuclear Science Symposium, Medical Imaging Conference and Room-Temperature Semiconductor Detector Workshop (NSS/MIC/RTSD), Strasbourg, France, 29 October-5 November 2016; IEEE: New York, NY, USA, 2016; pp. 1-4.

98. Grigoriev, D.N.; Akhmetshin, R.R.; Babichev, E.A.; Borovlev, Y.A.; Chistokhin, I.B.; Ivannikova, N.V.; Kazanin, V.F.; Kuznetsov, G.N.; Postupaeva, A.G.; Shlegel, V.N.; et al. The radiation hard BGO crystals for astrophysics applications. IEEE Trans. Nucl. Sci. 2014, 61, 2392-2396. [CrossRef]

99. Ongena, J.; Ogawa, Y. Nuclear fusion: Status report and future prospects. Energy Policy 2016, 96, 770-778. [CrossRef]

100. Duong, H.H.; Heidbrink, W.W. Confinement of fusion produced MeV ions in the DIII-D tokamak. Nucl. Fusion 1993, 33, 211. [CrossRef]

101. Garcia-Munoz, M.; Fahrbach, H.U.; Neuhauser, J.; Zohm, H.; Herrmann, A.; Rohde, V.; Team, A.U. Fast Ion Loss Diagnostic in ASDEX Upgrade. In Proceedings of the 32nd EPS Conference on Plasma Physics Combined with the 8th International Workshop on Fast Ignition of Fusion Targets, Tarragona, Spain, 27 June-1 July 2005.

102. Jiménez-Ramos, M.C.; García López, J.; García-Muñoz, M.; Rodríguez-Ramos, M.; Carmona Gázquez, M.; Zurro, B. Characterization of scintillator materials for fast-ion loss detectors in nuclear fusion reactors. Nucl. Instrum. Methods Phys. Res. Sect. B Beam Interact. Mater. Atoms 2014, 332, 216-219. [CrossRef]

103. Kiptily, V.G.; Cecil, F.E.; Medley, S.S. Gamma ray diagnostics of high temperature magnetically confined fusion plasmas. Plasma Phys. Control. Fusion 2006, 48, R59. [CrossRef]

104. Nishiura, M.; Doi, K.; Taniike, A.; Matsuki, T.; Shimazoe, K.; Mushiake, T.; Yoshino, M.; Nagasaka, T.; Fujimoto, Y.; Fujioka, K. Ion-induced gamma-ray detection of fast ions escaping from fusion plasmas. Rev. Sci. Instrum. 2014, 85, 11E804. [CrossRef]

105. Cazzaniga, C.; Nocente, M.; Tardocchi, M.; Rebai, M.; Pillon, M.; Camera, F.; Giaz, A.; Pellegri, L.; Gorini, G. Response of $\mathrm{LaBr}_{3}(\mathrm{Ce})$ scintillators to $14 \mathrm{MeV}$ fusion neutrons. Nucl. Instrum. Methods Phys. Res. Sect. A Accel. Spectrometers Detect. Assoc. Equip. 2015, 778, 20-25. [CrossRef]

106. Normand, S.; Iltis, A.; Bernard, F.; Domenech, T.; Delacour, P. Resistance to $\gamma$ irradiation of $\mathrm{LaBr}_{3}: \mathrm{Ce}_{\text {and }} \mathrm{LaCl}_{3}: \mathrm{Ce}$ single crystals. Nucl. Instrum. Methods Phys. Res. Sect. A Accel. Spectrometers Detect. Assoc. Equip. 2007, 572, 754-759. [CrossRef]

107. Park, C.H.; Lee, A.; Kim, R.; Moon, J.H. Evaluation of the detection efficiency of LYSO scintillator in the fiber-optic radiation sensor. Sci. Technol. Nucl. Install. 2014, 2014, 248403. [CrossRef]

108. Paganetti, H. Range uncertainties in proton therapy and the role of Monte Carlo simulations. Phys. Med. Biol. 2012, 57, R99. [CrossRef] [PubMed]

109. Min, C.H.; Lee, H.R.; Kim, C.H.; Lee, S.B. Development of array-type prompt gamma measurement system for in vivo range verification in proton therapy. Med. Phys. 2012, 39, 2100-2107. [CrossRef]

110. Pausch, G.; Berthold, J.; Enghardt, W.; Römer, K.; Straessner, A.; Wagner, A.; Werner, T.; Kögler, T. Detection systems for range monitoring in proton therapy: Needs and challenges. Nucl. Instrum. Methods Phys. Res. Sect. A Accel. Spectrometers Detect. Assoc. Equip. 2020, 954, 161227. [CrossRef]

111. Novotný, P.; Linhart, V. Radiation damage study of thin YAG: Ce scintillator using low-energy protons. J. Instrum. 2017, 12, P07021. [CrossRef]

112. Min, C.-H.; Kim, C.H.; Youn, M.-Y.; Kim, J.-W. Prompt gamma measurements for locating the dose falloff region in the proton therapy. Appl. Phys. Lett. 2006, 89, 183517. [CrossRef]

113. Biegun, A.K.; Seravalli, E.; Lopes, P.C.; Rinaldi, I.; Pinto, M.; Oxley, D.C.; Dendooven, P.; Verhaegen, F.; Parodi, K.; Crespo, P. Time-of-flight neutron rejection to improve prompt gamma imaging for proton range verification: A simulation study. Phys. Med. Biol. 2012, 57, 6429. [CrossRef] [PubMed]

114. Diblen, F.; Buitenhuis, T.; Solf, T.; Rodrigues, P.; van der Graaf, E.; van Goethem, M.-J.; Brandenburg, S.; Dendooven, P. Radiation hardness of dsipm sensors in a proton therapy radiation environment. IEEE Trans. Nucl. Sci. 2017, 64, 1891-1896. [CrossRef] 